\title{
Enzymatic synthesis of fluorinated compounds
}

\author{
Xinkuan Cheng ${ }^{1}(1) \cdot$ Long $^{M^{1}}$
}

Received: 4 August 2021 / Revised: 16 September 2021 / Accepted: 18 September 2021 / Published online: 9 October 2021

(c) The Author(s), under exclusive licence to Springer-Verlag GmbH Germany, part of Springer Nature 2021

\begin{abstract}
Fluorinated compounds are widely used in the fields of molecular imaging, pharmaceuticals, and materials. Fluorinated natural products in nature are rare, and the introduction of fluorine atoms into organic compound molecules can give these compounds new functions and make them have better performance. Therefore, the synthesis of fluorides has attracted more and more attention from biologists and chemists. Even so, achieving selective fluorination is still a huge challenge under mild conditions. In this review, the research progress of enzymatic synthesis of fluorinated compounds is summarized since 2015, including cytochrome P450 enzymes, aldolases, fluoroacetyl coenzyme A thioesterases, lipases, transaminases, reductive aminases, purine nucleoside phosphorylases, polyketide synthases, fluoroacetate dehalogenases, tyrosine phenol-lyases, glycosidases, fluorinases, and multienzyme system. Of all enzyme-catalyzed synthesis methods, the direct formation of the $\mathrm{C}-\mathrm{F}$ bond by fluorinase is the most effective and promising method. The structure and catalytic mechanism of fluorinase are introduced to understand fluorobiochemistry. Furthermore, the distribution, applications, and future development trends of fluorinated compounds are also outlined. Hopefully, this review will help researchers to understand the significance of enzymatic methods for the synthesis of fluorinated compounds and find or create excellent fluoride synthase in future research.

Key points

- Fluorinated compounds are distributed in plants and microorganisms, and are used in imaging, medicine, materials science.

- Enzyme catalysis is essential for the synthesis of fluorinated compounds.

- The loop structure of fluorinase is the key to forming the C-F bond.
\end{abstract}

Keywords Enzymatic synthesis $\cdot$ Fluorinase $\cdot$ C-F bonds $\cdot$ Fluorinated compounds $\cdot$ Applications of fluorides

\section{Introduction}

Fluorine has different physical and chemical properties from other elements, including bond length, van der Waals radius, van der Waals volume of the atom, and electronegativity of elements (Meanwell 2018). Unlike other halogens (chlorine, bromine, iodine, astatine, and tennessine),

Long Ma

malong@tust.edu.cn; woshimalong1983@163.com

1 State Key Laboratory of Food Nutrition and Safety, Key Laboratory of Industrial Microbiology, Ministry of Education, Tianjin Key Laboratory of Industry Microbiology, National and Local United Engineering Laboratory of Metabolic Control Fermentation Technology, College of Biotechnology, Tianjin University of Science \& Technology, No. 29, Thirteenth Street, Binhai New District, Tianjin 300457, China non-polarizable fluorine does not participate in halogen bonding. Due to its non-polarizability, strong electrostatic interactions will be formed, resulting in attractiveness or repulsion (Yang et al. 2015). Moreover, fluorine can change the $\mathrm{p} K_{\mathrm{a}}$, affinity, dipole moment, stability, lipophilicity, and bioavailability of adjacent groups (Dos Santos et al. 2020; Khosravan et al. 2017; Muller et al. 2007). Therefore, the target compounds doped with fluorine are endowed with stronger activity and stability, longer half-life, and better bioabsorbability (Moschner et al. 2019; Ni and $\mathrm{Hu} 2016$; Reichel and Karaghiosoff 2020), especially in the fields of pharmaceutical intermediates (Gillis et al. 2015; Swallow 2015; Zhdankin et al. 2017; Zou et al. 2019), cancer treatment (Meanwell et al. 2020), antiviral agents (Pomeisl et al. 2019), photovoltaics, diagnostic probes and bioinspired materials (Moschner et al. 2019). Besides, natural proteins incorporating fluorinated amino acids showed also many unique characteristics, which are used in the biotherapeutics 
protein-protein interaction and the synthesis of high valueadded chemicals (Arias et al. 2020; Awad and Ayoup 2020; Bucci et al. 2019; Liu et al. 2019; Mei et al. 2020a; Remete et al. 2018; Sisila et al. 2021; Vaughan et al. 2016; Wang and Matthews 2020; Won et al. 2019).

Unfortunately, fluorinated natural products are extremely rare in nature, which limits the application of fluorinecontaining compounds. Accordingly, the artificial synthesis of fluorinated compounds has become an important alternative in modern society. However, the formation of C-F bonds through nucleophilic fluorination reactions has been progressing slowly. The main reason is that fluorinated compounds react poorly and fluoride ion is easily solvated $\left(\triangle G^{\circ}>450 \mathrm{~kJ} / \mathrm{mol}\right)$ in protic media (Liang et al. 2017; Markakis et al. 2020; Mennie et al. 2018; Scheidt et al. 2018). Hence, they have the strongest hydration of halide so that the huge kinetic inertia needs to be overcome to promote this reaction. To realize the artificial synthesis of fluorinated compounds, many chemical catalysis methods have been developed and used to synthesize various fluorine-containing compounds including $\left[{ }^{18}\right.$ F]6-fluoro-L-3,4-dihydroxy-phenylalanine (Mossine et al. 2020), ${ }^{18} \mathrm{~F}$-fluoro- $\alpha$-methyl tyrosine, ${ }^{18} \mathrm{~F}$-prostate-specific membrane antigen (PSMA)-1007 (Giesel et al. 2017), and ${ }^{18}$ F-fluoro- $\alpha$-methyl phenylalanine $\left({ }^{18}\right.$ F-FAMP) (Hanaoka et al. 2019; Yamaguchi et al. 2020).

Nonetheless, these conventional chemical synthesis methods required precious metals, toxic and contaminating chemical reagents, high temperature, high pressure, extreme conditions, and the protection and deprotection of groups. This is not conducive to the sustainable development of green chemicals and the global economy. In contrast, the biosynthesis methods are good partners/supplements/ alternatives in the field of chemical synthesis, especially for fluorinated compounds. The biosynthesis methods are divided into fermentation methods and enzyme-based biocatalysis methods. Through fermentation methods, various fluorinated compounds can be synthesized by engineered microorganisms that integrated substrate transporters, product degradation pathways, fluoride ion channels, fluorideresponsive riboswitch, orthogonal T7 RNA polymerase, or chromosome (Calero et al. 2020; Jiang et al. 2018; Markakis et al. 2020; Rivera-Chavez et al. 2017; Sester et al. 2020; Thuronyi et al. 2017). However, some factors limit its application, including complex regulatory networks and the toxic effects of fluoride on living microorganisms. For enzymebased biocatalysis, it has the advantages of energy-saving, environmental protection, safety, high selectivity, atomic economy, convenient operation, and mild reaction conditions (Council et al. 2020; Fryszkowska and Devine 2020; Hauer 2020; Honig et al. 2017; Latham et al. 2018; Menon et al. 2020; Minges and Sewald 2020; O'Hagan and Deng 2015; Odar et al. 2015; Sandoval and Hyster 2020; Tong et al.
2019; Wu et al. 2020a). Hence, it has attracted more and more attention from biologists and chemists. In this review, diverse methods are introduced for the synthesis of fluorinated compounds catalyzed by different enzymes in recent years, especially fluorinase that can form the C-F bond with the selective catalytic mechanism (Fig. 1). Combined with the distribution, enzymatic synthesis methods, and applications of fluorinated compounds, this review will attract more scientists to participate in the field of fluorobiochemistry.

\section{Distribution of fluorinated natural products}

Since the discovery of the first fluorinated natural product, it has been more than 70 years. Fluorinated natural products are only distributed in fewer tissues. Although fluorides have also been found in animals, there is no direct evidence that fluorinated natural products can be synthesized by animals (Harper and O'Hagan 1994). Fluorides are obtained by animals mainly by eating foods containing fluorinated natural products. Plants and microorganisms have developed a huge ability to biosynthesize secondary metabolites, some of which are fluorinated natural products of various structures. However, there are still very few fluorinated natural products found in nature. The main known fluorinated natural products in plants and microorganisms are as follows (Fig. 2).

\section{Fluorinated natural products in plants}

Fluoroacetate was first discovered from plant gifblaar (Dichapetalum cymosum) in 1943 (Toit 1943). It is also the most common fluorinated natural product and has been identified in more than 40 higher plants. These plants that produce fluoroacetate mainly come from the families of Malpighiaceae, Fabaceae, Dichapetalaceae, Rubiaceae, and Bignoniaceae (Grobbelaar and Marion Meyer 1990; Lee et al. 2014). Fluoroacetate-containing plants grow all over the world, especially in Africa, Australia, and South America (Leong et al. 2017). Due to the toxicity of fluoroacetate, it is generally believed that these plants produce fluoroacetate for the defense of herbivores (Leong et al. 2017). Especially Dichapetalum braunii, its seeds contain up to $8000 \mathrm{ppm}$ of fluoroacetate, which is extremely defensive and even lethal (O'Hagan and B. Harper 1999). In addition, $(2 R, 3 R)$-2-fluorocitrate was also found to be present in the West African shrub Dichapetalum toxicarium and forage plants (soya bean, alfalfa, and crested wheatgrass) (Carvalho and Oliveira 2017; Harper and O'Hagan 1994; O'Hagan and Deng 2015; Ren et al. 2020; Zhang et al. 2019c). Despite the great interest, the physiological role of fluorinated natural products is not fully understood in higher plants. If fluoroacetate is for self-defense, are other natural products 
Fig. 1 Enzymatic synthesis of fluorinated compounds
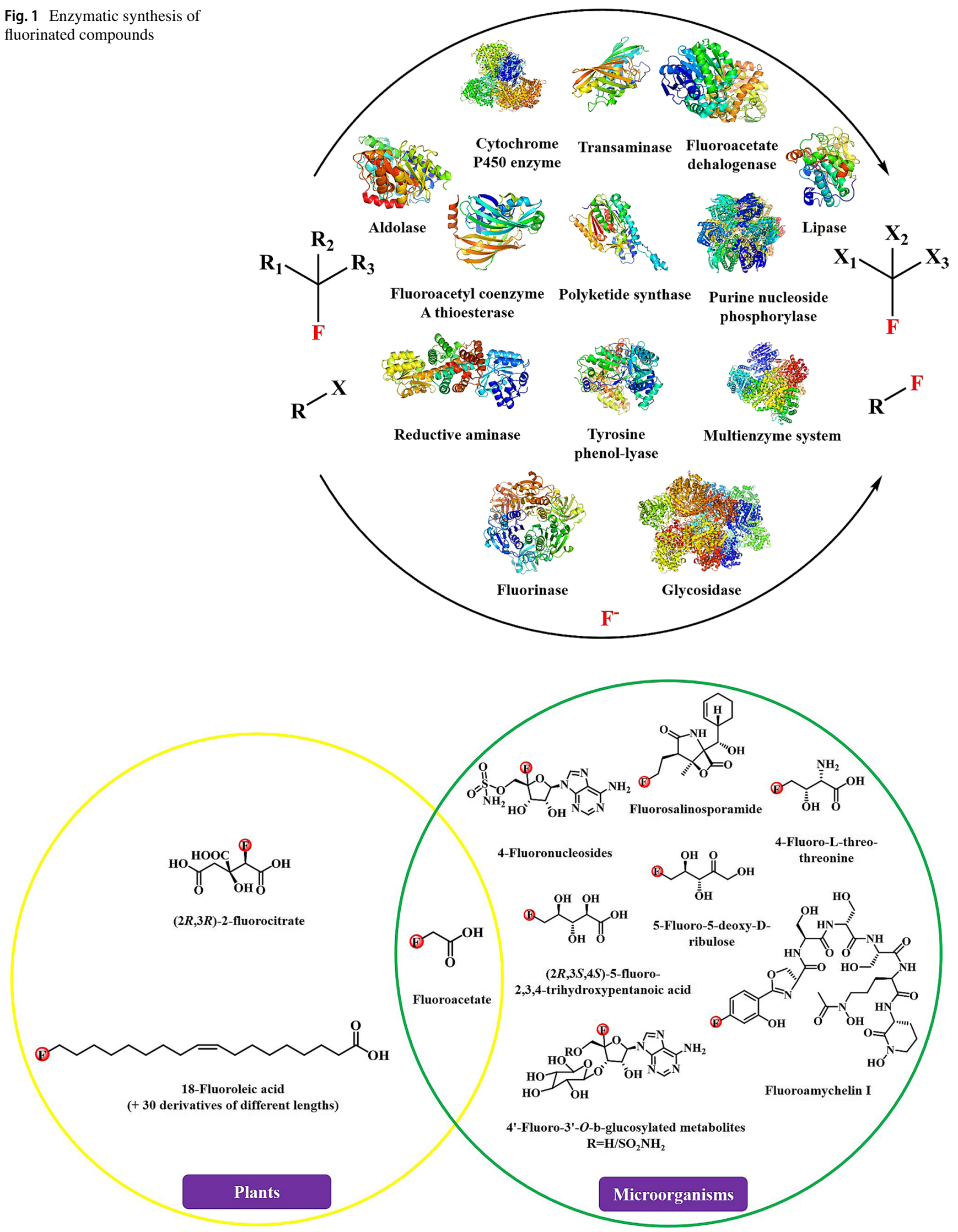

Fig. 2 Known fluorinated natural products 
of fluorination involved in the synthesis of metabolites or proteins? There are still many areas to be explored.

\section{Fluorinated natural products in microorganisms}

Fluoroacetate is also produced by various microorganisms, including S. cattleya, Streptomyces sp. MA37, Norcardia brasiliensis, Actinoplanes sp. N902-109, Actinopolyspora mzabensis, and Streptomyces xinghaiensis NRRL B24674 (Deng et al. 2014; Huang et al. 2014; Ren et al. 2020; Sanada et al. 1986; Sooklal et al. 2020). In addition to fluoroacetate, fluorinated threonine is another fluorinated natural product derived from fluoride-producing microorganisms. Moreover, it is also the only fluorinated amino acid found in nature. It should be noted that a new type of fluorometabolite ((2R3S4S)-5-fluoro-2,3,4-trihydroxypentanoic acid) was identified in Streptomyces sp. MA37 except for fluoroacetate and fluorinated threonine (Ma et al. 2015). This also showed that there is a unique fluoride metabolism pathway in Streptomyces sp. MA37. In addition to the above fluorinated natural products, microorganisms also produce other fluorinated natural products mainly including $4^{\prime}$-fluoro-3'$O$ - $\beta$-glucosylated metabolites (F-Mets I and II) (Feng et al. 2019), 4-fluoronucleosides (Zhang et al. 2019c), fluorosalinosporamide (O'Hagan and Deng 2015), and 5-fluoro-5-deoxy-D-ribulose (5-FDRul) (Wu et al. 2020b). Like plants, the physiological role and mechanism of fluorinated natural products are still a mystery in microorganisms.

\section{Enzymatic synthesis of fluorinated compounds}

\section{Cytochrome P450 enzymes}

Cytochrome P450 enzymes (P450s) belong to the superfamily of heme monooxygenases and are involved in the synthesis and degradation of many metabolites in actinomycetes. P450s can catalyze a variety of different reactions, mainly including dehydrogenation, epoxidation, dealkylation, $\mathrm{C}-\mathrm{C}$ bond formation or cleavage, $\mathrm{C}-\mathrm{N}$ bond formation, and hydroxylation (Chen and Arnold 2020; Iizaka et al. 2021). Therefore, various fluorinated compounds can be synthesized through different types of reactions mediated by P450s. This is an effective strategy to incorporate fluoroalkyl groups through the conversion of $\mathrm{C}\left(s p^{3}\right)$-H bonds to fluorocarbon alkyl bonds (McAtee et al. 2018). To synthesize organic fluorocarbon alkanes with $\alpha-\mathrm{CF}_{3}$, a biocatalytic platform was developed based on cytochrome P450 (Fig. 3A) (Huang et al. 2019). Through this platform, diverse $\alpha-\mathrm{CF}_{3}$ organoborons were obtained from $400 \mathrm{mM}$ Lewis-base borane complexes and trifluorodiazo alkanes (ee $=85-99 \%)$. Similarly, various organofluorine compounds with $S$-stereoselectivity were also obtained from $10 \mathrm{mM} \mathrm{N}$-aryl pyrrolidine and $20 \mathrm{mM}$ 2,2,2-trifluoro-1-diazoethane (ee > 99\%) (Zhang et al. 2019b). Notably, engineered P450 completely reversed the enantioselectivity of the products through directed evolution $(R$-stereoselectivity, ee $>99 \%)$. Moreover, fluorinated compounds can also be synthesized by $\mathrm{P} 450$ through nitrification reaction. Aromatic nitration is an important industrial process for the production of many chemicals. Cytochrome P450 enzyme from Streptomyces scabies 87.22 TxtE is the only enzyme that can directly catalyze the nitrification reaction so far (Zuo et al. 2016). To expand its application potential, fluorinated nitro-tryptophan analogs were obtained by P450TxtE from 1.5 mM 4-F-DL-tryptophan and 5-F-L-tryptophan in a $10 \mathrm{~mL}$ reaction system.

Among all the reaction types catalyzed by $\mathrm{P} 450$, the hydroxylation reaction is the most important type of reaction. Thus, the fluorinated derivative of $N$-(1-adamantyl)1-pentyl-1H-indazole-3-carboxamide (5F-AKB48) was obtained in vitro hydroxylation reaction (Pinson et al. 2020). Moreover, the 5F-AKB48 is the main component of cannabinoids (SCs), and the experiments showed that P450s from humans can oxidize 5F-AKB48 to fluoride with different hydroxyl groups. Interestingly, fluorine-containing compounds are also activators in the P450-mediated hydroxylation process. With the assistance of perfluorinated decoy molecules (PFC), the hydroxylation rate was significantly enhanced for unnatural substrate cycloalkanes by $\mathrm{P} 450$ from Bacillus megaterium (Dezvarei et al. 2018). In addition to bioenzymatic methods, $P 450$ can also realize the biosynthesis of fluorides through chemoenzymatic methods. For common organic molecules, one or more non-activated sites were selectively fluorinated by P450 and nucleophilic fluorination reagent diethylaminosulfur trifluoride (DAST) (Figure S1) (Obach et al. 2016; Rentmeister et al. 2009). In this process, monofluorine and polyfluorine compounds were synthesized through a two-step chemical enzymatic method. Especially for cyclic fluorides (steroidal analogs), high regioselectivity (55-100\%) and yields (>60\%) could be achieved by various P450 mutants and DAST. It is just that the use of chemical reagents makes the entire catalytic process less economical and environmentally friendly. It is worth noting that the ability of P450s to synthesize fluorides is also their physiological function in some organisms. Such as 6:2 fluorotelomer sulfonic acid (6:2 FTSA) is widely used in water-based film-forming foam as a new type of perfluorooctane sulfonic acid. In earthworms (Eisenia fetida), studies have shown that P450 is involved in the biotransformation of 6:2 FTSA (Zhao et al. 2021). Similarly, this function is also proven in pumpkin (Cucurbita maxima $\mathrm{L}$.) (Zhao et al. 2019a). 
A

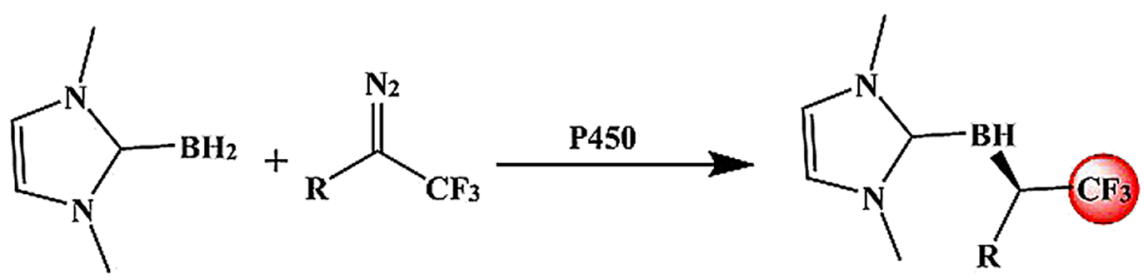

Borane complexes Trifluorodiazo alkanes

$\alpha-\mathrm{CF}_{3}$ organoborons

B<smiles></smiles>
fluoroarabinose

Fluorobenzimidazole bases

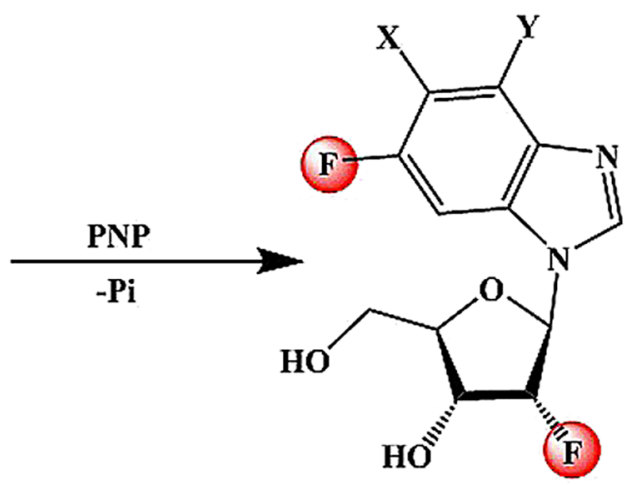

$\mathrm{X}=\mathrm{OCH}_{3} / \mathrm{H} / \mathrm{F}$

$\mathbf{Y}=\mathbf{H} / \mathrm{F}$

$2^{\prime}$-Deoxy-2'-fluoro-1-( $\beta$-Darabinofuranosyl)benzimidazoles

C

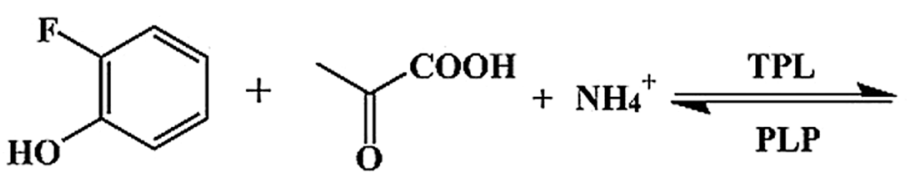

$o$-Fluorophenol

Pyruvate<smiles>N[C@@H](Cc1ccc(O)c([125I])c1)C(=O)O</smiles>

3-Fluoro-L-tyrosine

Fig. 3 The fluorinated compounds were obtained by combination reactions. A) The P450-mediated biocatalytic platform for the synthesis of $\alpha-\mathrm{CF}_{3}$ organoborons; B) Various modified $2^{\prime}$-deoxy-2'-fluoro-

As such, various fluorinated compounds can be obtained through diverse reactions mediated by P450. However, it is still necessary to further improve the issues of thermal stability, regional and stereo specificity of P450. Moreover, P450 must co-express the electron transport chain to perform its biological functions. These disadvantages are being overcome by experts in the field of synthetic biology. Synthetic biology is a cross-discipline that combines biology and engineering. It aims to achieve the goal of de novo synthesis of organisms through genetic design and construction of new biological elements and artificial gene circuits. In the future, synthetic biology is expected to combine interdisciplinary disciplines to use $\mathrm{P} 450$ for the de novo synthesis of fluorinated compounds.

\section{Purine nucleoside phosphorylases}

Purine nucleoside phosphorylase (E.C. 2.4.2.1, PNP) is a well-known drug target including cancer and immunodeficiency diseases (Pant et al. 2021; Parker et al. 2020).
$\beta$-D-arabinofuranosyl benzimidazoles were synthesized by the chemoenzymatic method based on PNP $\left(\mathrm{P}_{\mathrm{i}}=\right.$ inorganic phosphate); $\left.\mathrm{C}\right)$ The biosynthetic of 3-fluoro-L-tyrosine catalyzed by TPL

PNP can reversibly catalyze phosphorolysis of purine nucleosides to form glycosidic bonds (Holanda et al. 2020; Stachelska-Wierzchowska and Wierzchowski 2020; Timofeev et al. 2020). Therefore, PNP is a significant catalyst in the metabolic pathway of purines and nucleosides, especially 2-fluoroadenosine and 2-fluorocordycepin (Kayushin et al. 2021). To obtain fluorinated nucleoside analogs with antiviral activity, a chemo-enzymatic method was developed based on PNP (Fig. 3B) (Kharitonova et al. 2016). In this process, four fluorides were synthesized from $5 \mathrm{mM}$ 1- $\alpha$-phospho-2-deoxy-2-fluoroarabinose and $1 \mathrm{mM}$ fluorobenzimidazole bases (Conversions of bases $=46-88 \%$; Yields $=40-55 \%$ ). This provides an effective route for the synthesis of fluorinated nucleoside analogs. Although there is no need for any coenzymes or cofactors to participate, the use of chemical reagents increases the pollution of the reaction. This does not meet the requirements of the green economy and will increase the pressure on subsequent environmental protection 
treatments. Accordingly, an important challenge of this route is to develop new biocatalysts without chemical reagents.

\section{Tyrosine phenol-lyases}

PLP-dependent tyrosine phenol-lyases (EC 4.1.99.2, TPLs) can reversibly synthesize L-tyrosine from phenol, pyruvate, and ammonia (Phillips et al. 2019; Rocha et al. 2019). Thus, a TPL-based process has been developed to obtain the fluorinated L-tyrosine analogs, a potential drug for the treatment of Parkinson's disease (Zhu et al. 2020a). Through the process, $o$-fluorophenol was transform into 3 -fluoro-L-tyrosine by TPL and the space-time yield reached $4.2 \mathrm{~g} / \mathrm{L} / \mathrm{h}$ in fedbatch fermentation $($ Conversion $=90.2 \%$; Yield $=95.1 \%$ ) (Fig. 3C). Similarly, other fluorinated L-tyrosine derivatives were also synthesized through TPL-catalyzed synthetic biological systems (Dennig et al. 2015; Li et al. 2020a; Won et al. 2019). Moreover, the donor substrates were generated in situ. In this process, L-lactate oxidase (LOX) and $\mathrm{P} 450_{\mathrm{BM} 3}$ were usually used to generate pyruvate and fluorinated phenol from L-lactate and fluorinated aromatic hydrocarbon, respectively. As such, this method is very promising for the large-scale production of fluorinated L-tyrosine and its derivatives. Moreover, this biocatalytic method is also an important measure to upgrade cheap bulk chemicals to high value-added chiral fluorides. Unfortunately, the low catalytic efficiency requires more machine learning-assisted directed evolution to improve.

\section{Aldolases}

$\beta$-Hydroxy- $\alpha$-amino acids and their fluorinated derivatives are key intermediates for many drugs, which were used for the treatment of Parkinson's disease immunodeficiency and inflammation (Rocha et al. 2019; Scott et al. 2017). Pyridoxal 5'-phosphate (PLP)-dependent aldolases are regarded as the key biocatalysts for the formation of $\mathrm{C}-\mathrm{C}$ bonds and have become powerful tools for the sustainable synthesis of complex molecules, especially fluorinated $\beta$-hydroxy- $\alpha$ amino acids through aldol condensation (Chen et al. 2019a; Fang et al. 2019; Zheng et al. 2020, 2021). The formation of two chiral stereocenters is the main feature of this reaction. Moreover, it is difficult to control the stereoselectivity of the two chiral centers at the same time. The introduction of the special fluorine element further increases this difficulty, so that the first stereoselective fluorine-aldol condensation reaction was established in 2016 (Saadi and Wennemers 2016). Subsequently, fluorine-substituted $\beta$-hydroxy- $\alpha$-amino acids are synthesized by $\mathrm{D} / \mathrm{L}$-threonine aldolases (D/L-TAs) (Fig. 4A) (Chen et al. 2017, 2019a). In these cases, fluorine is not in the chiral center but the side chain. Various fluorinated D/L-threo/erythro- $\beta$-hydroxy- $\alpha$ amino acids were obtained from 5-100 mM aromatic fluorine substituted aldehydes and 10 equivalents of glycine (Conversions of aldehydes $=29.8-92.8 \%$ ). Similarly, fluorinated L-threo-threonine was also biosynthesized by 4-fluorothreonine transaldolase (FTase) from L-threo-threonine and fluoroacetaldehyde (Figure S2) (Wu et al. 2020c). Besides, chiral organofluorines have also been synthesized through a chemo-enzymatic method based on type II pyruvate aldolase (Fang et al. 2019). The donor binding and enolization can only be activated by divalent metal cations. In this process, $50 \mathrm{mM}$ fluoropyruvate and twelve aldehydes were synthesized corresponding to $\beta$-fluoro- $\alpha$-hydroxy compounds by pyruvate aldolase, $1 \mathrm{mM} \mathrm{MgCl}$, and $\mathrm{H}_{2} \mathrm{O}_{2}$ (Conversions of polar aldehydes $=80-100 \%$; Conversions of nonpolar aldehydes $=10-70 \%)$ (Figure S3). In all reactions catalyzed by

A

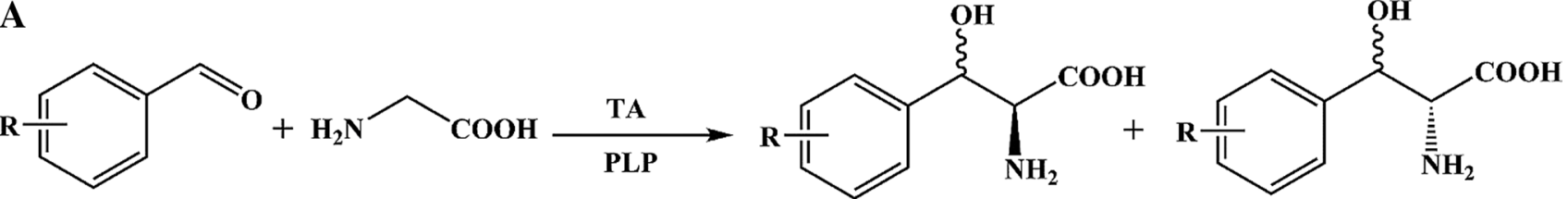

Fluorinated phenylacetaldehyde
(1) $\mathrm{R}=\boldsymbol{o}-\mathrm{F}$

(2) $\mathbf{R}=m-\mathrm{F}$

(3) $\mathrm{R}=p-\mathrm{F}$

\section{Fluorinated L-threo/erythro $\beta$-hydroxy- $\alpha$-amino acids}

Fluorinated D-threo/erythro $\beta$-hydroxy- $\alpha$-amino acids

B

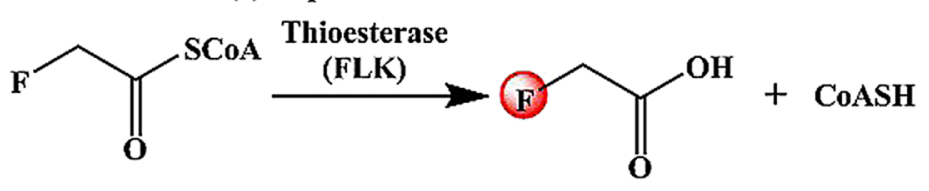

Fluoroacetyl-CoA

Fluoroacetate

Fig. 4 The fluorinated compounds with hydroxyl group were obtained. A) Synthesis of fluorinated $\beta$-hydroxy- $\alpha$-amino acids employing threonine aldolase; B) Biosynthesis of fluoroacetate catalyzed by FLK 
aldolases, control of regio and stereoselectivity is the key to the reaction. This is also one of the future development directions of aldolases.

\section{Fluoracetyl coenzyme A thioesterases}

Fluoroacetyl coenzyme A thioesterases (EC 3.1.2.29, FLKs) can catalyze the decomposition of fluoroacetyl coenzyme A (fluoroacetyl-CoA) into fluoroacetate and CoA, and does not catalyze acetyl-CoA (Fig. 4B) (Huang et al. 2006; Thuronyi and Chang 2015). FLK has extremely high specificity for fluorinated substrates, and its hydrolysis efficiency is 10,000-fold that of non-fluorinated substrates (Weeks and Chang 2012). To understand the mechanism of selective fluorination, a comprehensive strategy was implemented for FLK including thermodynamic, kinetic, and biophysical experiments. These studies indicated that entropy drive mediated by hydrophobicity and solvation is the key to selective fluorination recognition, especially the substratebinding controlled by the active site Phe36 (Figure S4) (Weeks et al. 2018). Moreover, the selectivity to the fluoroacetyl-CoA substrate not only depends on the polarization provided by the negatively charged fluorine substitution but also on the molecular recognition of fluorine during the formation of acyl-FLK intermediate (Weeks et al. 2014). It should be noted that FLK itself also has important physiological functions. FLK can prevent the further metabolism of fluoroacetyl-CoA to 4-hydroxy-trans-arachidic acid ester, a lethal inhibitor of the tricarboxylic acid cycle (Dias et al. 2010). The specific catalytic activity of FLK has great advantages in physiology. In addition, it also has extremely high selectivity for the synthesis of specific fluorinated products. However, more directed evolution engineering should be carried out to obtain fluorinated acetic acid analogs with diverse structures requires. Moreover, the rational use of $\mathrm{CoASH}$ is also an issue worth considering in the process of biosynthesis.

\section{Transaminases}

PLP-dependent transaminases are important biocatalysts for the synthesis of chiral amines (Patil et al. 2018). For fluorinated chiral amines, an asymmetric amination method was established based on transaminase (Fig. 5A) (LópezIglesias et al. 2017). $R$-fluoroamines or $S$-fluoroamines were obtained from $50 \mathrm{mM}$ 1-(5/6-fluoropyridin-3-yl) ethan-1-one or 1-(6-(trifluoromethyl)pyridin-3-yl)ethan-1one by $R / S$-selective transaminase (Conversions $=75-94 \%$; $\left.\mathrm{ee}_{\mathrm{R} / \mathrm{S}}>99 \%\right)$. D/L-Alanine $(250 \mathrm{mM})$ was used as amino donors for transaminase. Similarly, methyl/trifluoromethyl diketone was also catalyzed by transaminase to fluoroamines (Figure S5) (González-Martínez et al. 2020b). Although the amination of two carbonyl groups will form three products in theory, transaminase only selectively modified smaller methyl ketones in practice. Consequently, the product 1-(4-(1-aminoethyl)phenyl)-2,2,2-trifluoroethan-1-one was obtained by amination of a carbonyl group ( $e e=98->99 \%$ ). To further produce chiral fluorinated hydroxylamine, alcohol dehydrogenase was subjected to a hydrogenation reaction to obtain the substrate of hydroxyketones. The hydroxyketones obtained were then converted chiral fluorinated hydroxylamines by transaminase (conversions $=84-90 \%$ ) (Figure S6). Since the reaction catalyzed by transaminase is reversible, the kinetic resolution reaction can be achieved to obtain fluoroamines from the corresponding racemate. Interestingly, the kinetic resolution reaction catalyzed by transaminase is promiscuous with hydrodefluorination and deamination (Cuetos et al. 2016). In the unconventional process mediated by catalytic promiscuity, a series of aromatic $\beta$-fluoroamines were obtained by kinetic resolution through transaminase-mediated hydrodefluorination/deamination reactions (Yields $=75-80 \%, e_{S}>99 \%$ ) (Figure S7). Notably, this protocol is the first case of using transaminase to catalyze promiscuousness and does not require amino acceptors. Even so, transaminases still require optically pure $\mathrm{D} / \mathrm{L}$-amino acids as amino donors. Expensive amino
Fig. 5 The fluorinated compounds were obtained by reductive amination. A) Asymmetric amination of ketones to fluorinated amines catalyzed by the transaminase; B) The reaction catalyzed by reductive aminase

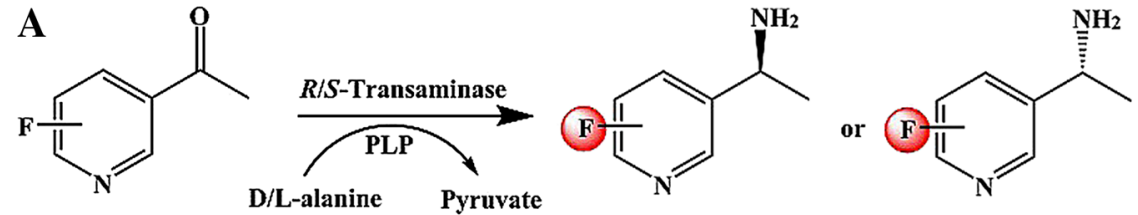

Ketones

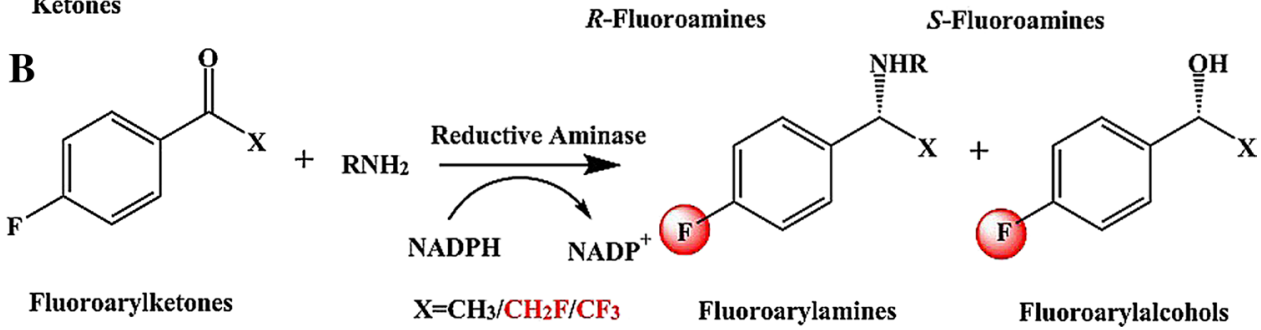


donors increase the cost of biocatalysis and bioconversion. The converted amino donors also increase the difficulty of separating the final products. Moreover, the limited recycling of the cofactor PLP also restricts the further promotion of this method.

\section{Reductive aminases}

Chiral fluoroamines are the key components of drug molecules, which can improve efficacy and slow down metabolism. In addition to transaminases, chiral fluoroamines can also be synthesized by reductive aminases, which belong to the imine reductase family (France et al. 2018). Reductive aminase showed high activity for the reductive amination of ketones for the synthesis of fluorinated amines (Aleku et al. 2017). Similar to transaminase, reductive aminase also exhibited a promiscuous reaction to reduce ketones to amines and alcohols (Fig. 5B) (González-Martínez et al. 2020a; Yang et al. 2021). Through reductive aminase, primary and secondary $\beta$-fluoroarylamines and fluoroarylalcohols were obtained from $5 \mathrm{mM}$ fluoroarylketones (Conversions $>90 \%$, ee $=85-99 \%$ ). As such, reductive aminase provides a sustainable and highly economical biocatalysis toolbox, which can synthesize fluorinated chiral amines and fluorinated chiral alcohols from readily available prochiral substrates. Moreover, inexpensive inorganic ammonium salts provide a lot of convenience as amino donors and do not produce by-products. Nonetheless, the high cost of the coenzyme NADPH is a major disadvantage. Therefore, various coenzyme circulation systems are usually integrated through glucose dehydrogenase or formate dehydrogenase. But it will undoubtedly be more perfect if the coenzyme preference of expensive NADPH is changed to cheap NADH.

\section{Polyketide synthases}

Polyketides are a class of complex natural products with multiple structures and biological activities, which are prolific sources of numerous different scaffolds (Maglangit et al. 2019; Tao et al. 2021). Polyketide synthases (PKSs) are multidomain megasynthetases and participate in the synthesis of numerous polyketide natural products in bacteria and fungi (Adrover-Castellano et al. 2021; Weissman 2016; Zhu et al. 2021). The introduction of fluorine-containing modules into the PKS system can bring fluorine into the scaffold of natural products, which is an important strategy for the synthesis of complex organic fluorides. Here, acetate is the basic element for the formation of polyketide natural products. Hence, the preparation of fluorinated polyketide has been investigated

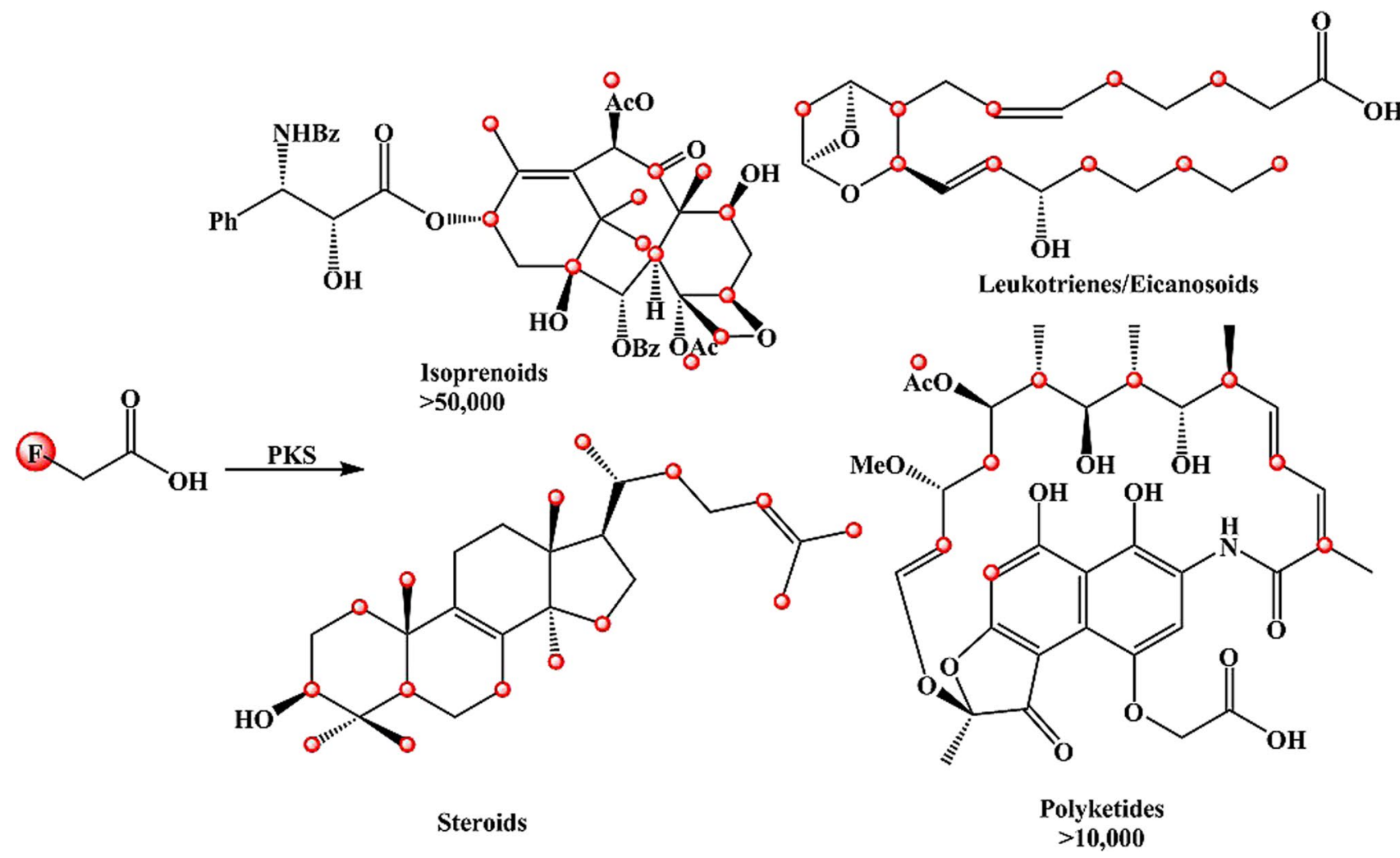

Fig. 6 The complex fluorinated compounds were obtained from fluoroacetate as the building block 
using PKS from fluoroacetate (Fig. 6) (Hong et al. 2008; Klopries et al. 2014; Walker et al. 2013; Wu et al. 2020a). Similarly, fluorinated polyketones can also be obtained from fluoromalonate and fluorobutyrate, which are derived from the basic building blocks malonate and butyric acid, respectively (Klopries et al. 2014; Thuronyi and Chang 2015; Thuronyi et al. 2017).

PKS has three necessary domains, including the ketone synthase (KS) domain, acyltransferase (AT) domain, and acyl carrier protein (ACP) domain (Robbins et al. 2016; Wang et al. 2021). The catalytic process showed that the inactivation of the AT domain can eliminate the selectivity to the fluorine-containing extension unit in the fluorinated polyketones biosynthesis system and initiate the $\mathrm{C}-\mathrm{C}$ bond formation mode independent of ACP ( $\mathrm{Ad}$ et al. 2017). Subsequently, the trans-AT complementary domain was incorporated to synthesize both monofluorinated and difluorinated products. Consequently, the use of the PKS module is expected to achieve a stable production method of fluorinated full-length polyketide and other complex products at a specific location. Due to the complexity of the structure of fluorinated polyketones, the selective synthesis mechanism of PKS remains to be elucidated. Therefore, this is a huge challenge for the selective synthesis of various fluorinated substituted polyketones. To explore the catalytic mechanism, more work needs to be done in the field of crystal structure analysis and mutation in the future.

\section{Lipases}

Lipases (EC 3.1.1.3) belong to the family of hydrolases. In the presence of organic solvents (such as stearic acids, triacylglycerides, and fatty acids), many substrates can be effectively catalyzed by lipases for acylation (Cavalcante et al. 2021; Huang et al. 2021; Marquez-Rodriguez et al. 2021). Besides, lipases are also excellent biocatalysts to obtain fluorinated compounds in the presence of organic solvents. For fluorinated 1-(pyridin-3-yl)ethanamines, ethyl methoxyacetate, and tetrahydrofuran were used as acylating agents and cosolvent, respectively (López-Iglesias et al. 2017). In this reaction, $100 \mathrm{mM}$ fluorinated racemic amines were converted to corresponding $R$-isomers and $S$-isomers through kinetic resolution (Conversions $=50 \%$; ee $_{S}=90-96 \%$; $\mathrm{ee}_{\mathrm{R}}=99 \%$ ). Similar to kinetic resolution, lipases can also catalyze enantioselective hydrolysis reactions to obtain $\beta$-fluorinated amino acids, which are key components of many natural products, drugs, and biologically active peptides (Shahmohammadi et al. 2020; Zhang et al. 2020b). In the presence of $i \mathrm{Pr}_{2} \mathrm{O}, \mathrm{Et}_{3} \mathrm{~N}$, and $\mathrm{H}_{2} \mathrm{O}, 25 \mathrm{mM}$ racemic fluorinated $\beta$-amino carboxylic ester hydrochloride salts were hydrolyzed into fluorinated $R$ - $\beta$-amino carboxylic ester enantiomers (Yields $=38-49 \%$, ee $=94->99 \%$ ) and fluorinated $S$ - $\beta$-amino acids (Yields $=48-49 \%$, ee $>99 \%$ ) (Fig. 7A). Likewise, many other types of fluorinated compounds were also obtained by lipases, like 2,2,2-trifluoroethyl trifluoromethyl sulfate, fluorinated polyesters, and meso-2,4,6-trifluoro-1,3,5,7-tetrahydroxyheptane-1,7-diacetate (Bentler et al. 2019; Snoch et al. 2019; Zhao et al.

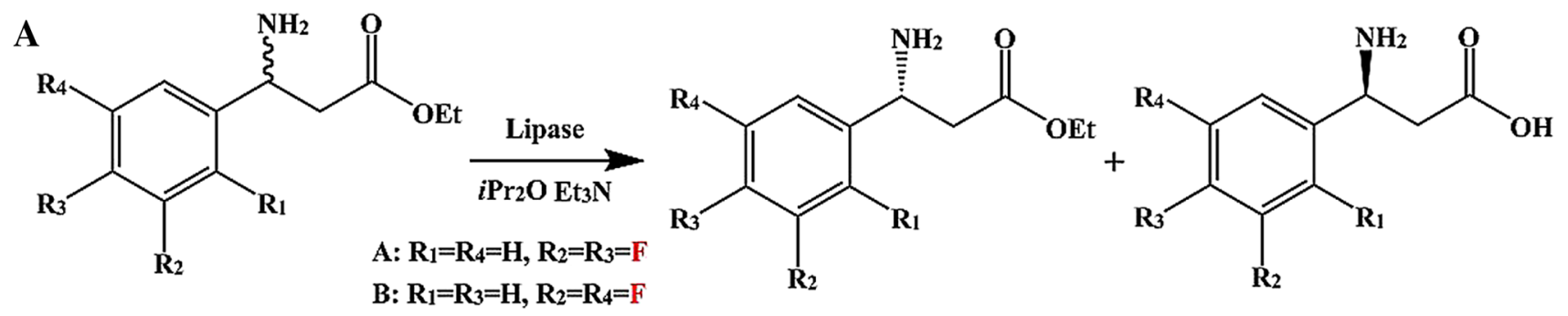

Racemic fluorinated $\beta$-amino carboxylic esters
C: $\mathbf{R}_{1}=\mathbf{R}_{2}=\mathbf{R}_{4}=\mathbf{H}, \mathbf{R}_{3}=\mathrm{F}$

D: $\mathbf{R}_{1}=\mathrm{F}, \mathbf{R}_{2}=\mathbf{R}_{4}=\mathrm{H}, \mathbf{R}_{3}=\mathrm{CF}_{3}$

E: $\mathbf{R}_{1}=\mathrm{F}, \mathbf{R}_{2}=\mathrm{R}_{4}=\mathrm{H}, \mathbf{R}_{3}=\mathrm{CH}_{3} \quad R$ - $\beta$-amino carboxylic esters

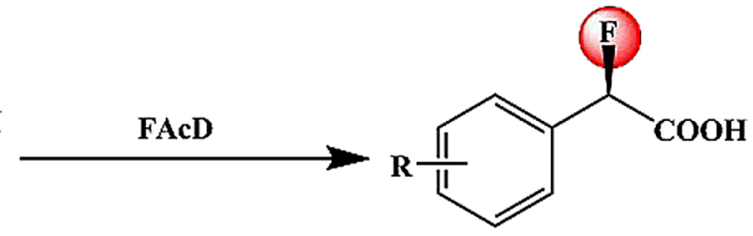

(R)-2-Fluoro-2-phenylacetic acid derivatives
Fluorinated $S$ - $\alpha$-amino acids

B

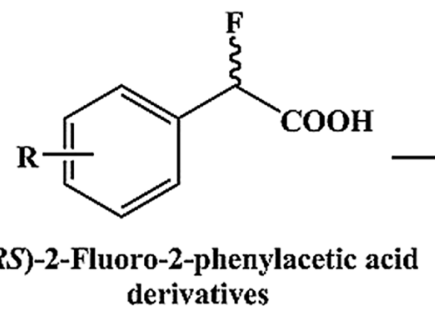

Fig. 7 The fluorinated compounds were obtained by kinetic resolution. A) Fluorinated $\beta$-amino acids/carboxylic esters were obtained by lipase; B) 2-Fluorocarboxylic acid derivatives were obtained by fluoroacetate dehalogenase 
2019b). Importantly, lipase has good resistance to organic solvents in addition to being able to catalyze cheap ester substrates. Thus, lipase is an excellent choice for catalytic reactions that require organic solvents to help dissolve substrates. Notably, the pollution of organic solvents to the environment must be carefully considered in this process. The organic solvent recycling device may become an alternative in the future.

\section{Fluoroacetate dehalogenases}

According to the "Stockholm Convention," all persistent organic pollutants are halogenated by fluorine, chlorine, or bromine. Therefore, dehalogenation is an important measure to control environmental pollution (Yue et al. 2020). Fluoroacetate dehalogenases (EC 3.8.1.3, FAcDs) are a class of enzymes that can cleave carbon-halogen bonds initiated by $\mathrm{S}_{\mathrm{N}} 2$ substitution (Kim et al. 2017; Miranda-Rojas et al. 2018; Wang et al. 2017). Accordingly, FAcD is an effective tool to control pollution through enzymatic biodegradation (Li et al. 2019). Interestingly, FAcD can not only degrade fluoride but also obtain fluoride by kinetic resolution of racemates (Fig. 7B) (Zhang et al. 2020a). In this process, $500 \mathrm{mM}(R S)$-2-fluoro-2-phenylacetic acid derivatives were transformed to corresponding $R$-isomers and $(R)$-2-hydroxy2-phenylacetic acid derivatives by FAcD (Conversion $=50 \%$, Yields of $R$-fluorocarboxylic acids $=58-97 \%$, ee $>97 \%$ ). Hence, FAcD can not only eliminate environmental pollution but also effectively synthesize high value-added organic fluorides. It is just that the maximum theoretical yield of kinetic resolution is only $50 \%$ and there are by-products. These limit the application of FAcD in the field of fluorides biosynthesis. Therefore, it will be a huge improvement if by-products are converted into products or a two-phase separation system can be developed for products and by-products.

\section{Glycosidases: $\beta$-mannosynthase and $\beta$-glucosidase}

Typical glycosidases can hydrolyze sugars at specific locations and types (Li and Fan 2020). Excitingly, the C-F bonds can be formed by glycosidases ( $\beta$-mannosynthase and $\beta$-glucosidase) through nucleophilic fluorination (Fig. 8A) (Nashiru et al. 2001; Zechel et al. 2001). This is the first enzyme catalyst with selective fluorination for C-F bonds discovered. Utilizing glycosidase, $23 \mathrm{mM}$ 2,5-dinitrophenyl $\beta$-mannoside and $2 \mathrm{M} \mathrm{KF}$ were successfully transformed to $\beta$-mannosyl fluoride. Unfortunately, this fluorinated compound has not been isolated. This is because the fluorinated compound formed can also serve as a glycosyl donor and continue to participate in the transglycosylation reaction to form new glycosidic bonds. This process will cause the formed C-F bond to be degraded. Therefore, it is difficult to accumulate fluorinated products. This is why this enzyme has not been widely used to synthesize fluorinated compounds. In the future, it may become possible to use this enzyme for the biocatalytic synthesis of fluoride by controlling the progress of the reaction. Besides, a specific fluorinated product separation device may be necessary to utilize glycosidases.

\section{Fluorinases}

In 2002, a fluorination enzyme (fluorinase) was isolated and identified from the soil bacterium Streptomyces cattelya for the first time (O'Hagan et al. 2002). The fluorinase (EC 2.5.1.63) is also called $5^{\prime}$-fluoro-5'-deoxyadenosine (5'-FDA) synthase, which participates in the secondary

A
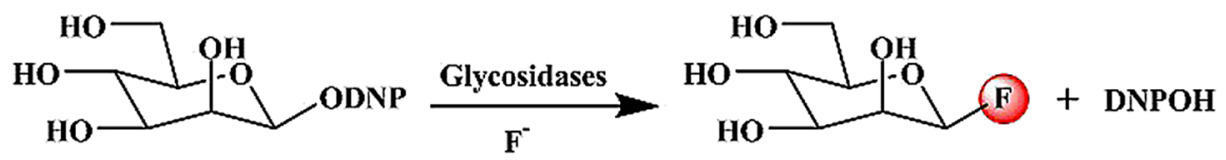

2,5-Dinitrophenyl $\beta$-mannoside

及-Mannosyl fluoride

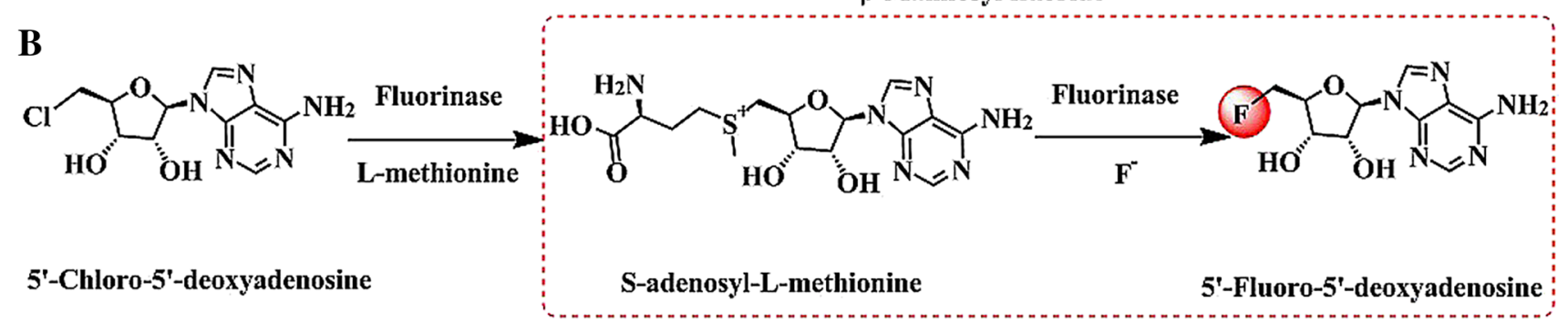

Fig. 8 The fluorinated compounds were obtained through the formation of C-F bond. A) $\beta$-Mannosyl fluoride was formed from 2,4-dinitrophenyl $\beta$-glycoside catalyzed by glycosidases $(\mathrm{DNP}=2,5$-dini- trophenyl); B) Two-step synthesis of fluorinated compounds by transhalogenation reaction catalyzed by fluorinase 
metabolism of fluorinated natural products. The fluorinase can catalyze the synthesis of 5'-FDA from S-adenosylL-methionine (SAM) and fluoride ion through nucleophilic attack to form a C-F bond (Fig. 8B, red dashed frame). As such, fluorinase has become an important biocatalyst for the synthesis of fluorinated nucleosides and their derivatives. Although fluorinase from $S$. cattleya had been applied to catalyze the non-natural substrates, a major drawback is that it exhibited reduced catalytic activity for unnatural substrates (Fraley and Sherman 2018). To overcome this obstacle, the directed evolution strategy was first implemented on fluorinase in 2016 (Sun et al. 2016; Thomsen et al. 2013). In this process, 23 sites were selected within $5 \AA$ of the substrate, and the best mutant F213Y/A279L was obtained after saturation mutation and high-throughput screening (1932 clones). The catalytic efficiency of mutant F213Y/A279L was significantly increased by 25 -fold compared to that of wild type for the non-natural substrate $5^{\prime}$-chloro-5'-deoxyadenosine (5'CIDA). In addition, the efficiency in synthesizing radioactive $5 '-\left[{ }^{18} \mathrm{~F}\right]$ FDA was also tripled compared to that of wild type. To expand the synthetic range of fluorinase, a new class of fluorinated nucleoside receptor agonists was synthesized from $0.1-0.2 \mathrm{mM}$ chlorinated precursors, $50 \mathrm{mM} \mathrm{KF}$, and $0.075 \mathrm{mM}$ L-SeMet $($ Conversion $=10 \%$, Yield $=3.5 \%)$ (Lowe et al. 2017). The agonist belongs to the analogs of $5^{\prime}$-FDA with a terminal functionalized ethynyl unit substituted at the C2 position. Similarly, the fluorinated RGD peptides and prostate-specific membrane antigen were also synthesized by fluorinase through transhalogenation reaction (Lowe et al. 2019b; Thompson et al. 2016a, 2015; Zhang et al. 2016). The above-mentioned reaction was a two-step process in nature. In the first step, $5^{\prime}$-CIDA was transformed into SAM in the presence of fluorinase and L-Met. In the next step, the producing SAM was transformed into 5'-FDA in the presence of fluorinase and fluoride ions (Fig. 8B).

Moreover, the first reaction is the rate-limiting step for the synthesis of fluorinated compounds. To overcome the rate-limiting step, two novel SAM-dependent chlorinases were discovered to improve the efficiency of the transhalogenation reaction in the first step reaction. Finally, a chlorinase-fluorinase coupling system was developed. Through this system, 5'-FDA and 5'-fluorodeoxy-2-ethynyladenosine (5'-FDEA) were synthesized efficiently from $0.2 \mathrm{mM} 5^{\prime}$-CIDA/5' -chlorodeoxy-2-ethynyladenosine (5'CIDEA), $0.1 \mathrm{mM}$ L-SeMet, and $80 \mathrm{mM} \mathrm{NaF}(98.04 \pm 0.27 \%$ and $91.60 \pm 0.13 \%$ yields, respectively) (Sun et al. 2018). Surprisingly, Phillip T. Lowe et al. found that intermediate products SAM and L-methionine are not necessary for synthesizing $5^{\prime}$-FDA through fluorinase (Lowe et al. 2019a). Fluorinase can directly catalyze the synthesis of $5^{\prime}$-FDA from 5'-ClDA, 5'-bromo-5'-deoxyadenosine (5'-BrDA), and $5^{\prime}$-iodo-5'-deoxyadenosine (5'-IDA) in the presence of fluoride ion without SAM and L-Met (Finkelstein Reaction).
Additionally, the highest conversion efficiency was obtained for the substrate $5^{\prime}-\mathrm{BrDA}(35 \%)$ compared with $5^{\prime}$-IDA (8\%) and $5^{\prime}-\mathrm{CIDA}(5 \%)$.

In addition to the catalytic process in vitro, the metabolic pathways of fluoride in microorganisms have also been elucidated, and related fluorinated natural products and biocatalysts have been confirmed (Figure S8). Unfortunately, there are few sources of fluorinases, which limits the development of effective biocatalysts for the synthesis of fluorinated compounds. Before 2016, only 5 fluorinases were identified and characterized from S. cattleya, Streptomyces sp MA37, Norcardia brasiliensis, Actinoplanes sp N902-109 and Streptomyces xinghaiensis NRRL B24674 (Deng et al. 2014; Ma et al. 2016; Ren et al. 2020). Until recently, the sixth fluorinase was identified from Actinopolyspora mzabensis (AmFLA) (Sooklal et al. 2020). Due to AmFLA was an inclusion body, it was refolded into soluble protein through $8 \mathrm{M}$ urea. The soluble AmFLA showed the specific activity of $0.44 \pm 0.03 \mu \mathrm{M} / \mathrm{min} / \mathrm{mg}$ for SAM at $\mathrm{pH} 7.2$ and $65^{\circ} \mathrm{C}$ (both the optimal conditions). Besides, AmFLA also exhibited comparatively thermostability that it still retained $26 \%$ catalytic activity at $25{ }^{\circ} \mathrm{C}$ for 2 months and $>70 \%$ catalytic activity at $80^{\circ} \mathrm{C}$ for $20 \mathrm{~min}$. Surprisingly, the specific activity of AmFLA was increased by $9.5 \%$ with the help of $1 \mathrm{mM}$ $\mathrm{Mg}^{2+}$. This is the first time that fluorinase was found to be metal ion-dependent. To improve the activity and stability, fluorinase was immobilized with fluoridated hydroxyapatite nanoflowers ( $\mathrm{Li}$ et al. 2020b). Under the same conditions, the activity of immobilized fluorinase is twice as high as the free enzyme. After $8 \mathrm{~h}$ of incubation at $30{ }^{\circ} \mathrm{C}, 80 \%$ of activity was retained for the immobilized fluorinase and only $48 \%$ for free fluorinase. Apart from immobilization methods, protein self-assembly is also an effective strategy to improve activity and stability (Tu et al. 2020). With the help of self-assembled tags, fluorinase was formed into a novel artificial enzyme with nanometer dimensions. Strikingly, the novel artificial fluorinase exhibited higher enzyme activity, thermal stability, and reusability than the original fluorinase. Notably, fluorinase is currently the only biocatalyst widely used in the synthesis of fluorinated compounds that can form the C-F bond. In particular, fluorinase has great application potential for the synthesis of radioactive fluorinated imaging tracers. However, only limited potential has been exploited for fluorinase. Therefore, there is still much work to be done as soon as possible, especially considering that there are only six fluorinase sources, only two fluorinase crystal structures, low enzyme activity and narrow substrate range.

\section{Multienzyme system}

Not all products of interest can be obtained through a single biocatalyst as desired. Inspired by the natural multi-enzyme catalytic system, many high value-added products have been 
obtained through the artificial multi-enzymatic system, especially fluorinated compounds (Table 1). Accordingly, the artificial multi-enzymatic system was established for fluorinated aromatic compounds, including L-amino acid deaminase (LAAD), $\alpha$-keto acid decarboxylase (ARO10), and aldehyde dehydrogenase (ALDH) (Figure S9) (Mao et al. 2020). Through the system, $10 \mathrm{mM} \mathrm{m}$-fluoro-D/Lphenylalanine was transformed to $m$-fluoro-phenylacetic acid with a conversion of $48 \%$ in $24 \mathrm{~h}$. The artificial multi-enzymatic system constructed has been proved to be effective in synthesizing non-natural fluorinated aromatic compounds without transferring intermediate products. Similarly, a multi-enzymatic system was performed with aromatic amino acid transaminase and hydroxymandelate synthase (HMS), producing fluoro-L-mandelic acid from $5 \mathrm{mM}$ fluoro-L-phenylalanine (Yield $=65 \pm 1.4 \%$, ee $>86 \%$ ) (Figure S10) (Youn et al. 2020). Moreover, ortho and meta fluorinated mandelic acids were also synthesized in the same method (Yields $=37 \pm 0.4 \%$ and $47 \pm 1.8 \%$ ). Also starting from substrate fluoro-L-phenylalanine, fluoro-benzyl alcohol was successfully synthesized in a multi-enzymatic system of five enzymes, including LAAD, HMS, L-mandelate dehydrogenase (LMDH), benzoylformate decarboxylase (BFD), and phenylacetaldehyde reductase (PAR) $($ Yield $=633.17 \mathrm{mg} / \mathrm{L}$ ) (Figure S11) (Liu et al. 2020).

Besides, a catalytic system coupled with TPL and tyrosine ammonia-lyase (TAL) was established to obtain the fluorinated unsaturated carboxylic acid (Figure S12) (Busto et al. 2016). This overcomes the shortcomings of by-products produced in the direct alkenylation process. During the TPL-TAL coupling process, $23 \mathrm{mM}$ fluorophenols and $46 \mathrm{mM}$ pyruvate were converted into fluoro-L-tyrosines by TPL. Subsequently, the intermediate products obtained were transformed to $p$-hydroxyfluorocinnamic acids by TAL (Yield $>95 \%$ ). Moreover, fluorinated galactoside was also synthesized by the multi-enzyme catalysis method (Figure S13) (Geissner et al. 2021). This is mainly because fluorinated galactoside can improve the stability of glycoprotein, and stable glycoprotein plays a vital role in the persistence of the therapeutic effect. In this process, $100 \mathrm{mM}$ 4-deoxy-4-fluoro- $N$-acetylhexosamine and $500 \mathrm{mM}$ pyruvate were transformed to 7 -modified sialic acid through porcine $N$-acyl-D-glucosamine 2-epimerase and sialic acid aldolase $($ Conversion $=95 \%$, Yield $=91 \%)$. Subsequently, the 7-modified sialic acid obtained was converted to 7-modified CMP-sialic acid (CMP = cytidine monophosphate) by CMP sialic acid synthetase and inorganic pyrophosphatase (Yield $=86 \%$ ). Ultimately, the 7-modified CMP-sialic acid obtained was transformed to (7F-)sialyl galactoside by sialyltransferase and alkaline phosphatase (Conversion $=100 \%$, Yield $=64 \%)$. The final results indicated that the half-life of the therapeutic glycoprotein was significantly provided by the incorporation of (7F-)sialyl galactoside synthesized.

The multi-enzyme synthesis of fluorine compounds can not only expand the application potential of enzymes as catalysts but also provide new ideas for the preparation of complex fluorinated products. Multi-enzyme catalysis can effectively shorten the transfer distance of intermediate products and accelerate the reaction rate. Moreover, the synthetic route can be realized from cheap substrates as starting substrates. However, there are still many challenges facing the development of the multi-enzymatic synthesis of fluorine compounds. First, the cost of the catalyst is increased due to the preparation of multiple enzymes. Second, the compatibility needs to be considered for multiple enzyme reaction conditions (for example, temperature, $\mathrm{pH}$, metal

Table 1 The multi-enzymatic systems of fluorinated compounds

\begin{tabular}{|c|c|c|c|}
\hline Entry & Substrates & Multi-enzyme catalyst & Products \\
\hline 1 & $m$-fluoro-D/L-phenylalanine & $\begin{array}{l}\text { L-amino acid deaminase } \\
\alpha \text {-keto acid decarboxylase } \\
\text { aldehyde dehydrogenase }\end{array}$ & $m$-fluoro-phenylacetic acid \\
\hline 2 & $o / m / p$-fluoro-L-phenylalanine & $\begin{array}{l}\text { aromatic amino acid transaminase } \\
\text { hydroxymandelate synthase }\end{array}$ & $o / m / p$-fluoro-L-mandelic acids \\
\hline 3 & fluoro-L-phenylalanine & $\begin{array}{l}\text { L-amino acid deaminase } \\
\text { hydroxymandelate synthase } \\
\text { L-mandelate dehydrogenase } \\
\text { benzoylformate decarboxylase } \\
\text { phenylacetaldehyde reductase }\end{array}$ & fluoro-benzyl alcohol \\
\hline 4 & $\begin{array}{l}\text { fluorophenols } \\
\text { pyruvate }\end{array}$ & $\begin{array}{l}\text { tyrosine phenol-lyase } \\
\text { tyrosine ammonia-lyase }\end{array}$ & p-hydroxyfluorocinnamic acids \\
\hline 5 & $\begin{array}{l}\text { 4-deoxy-4-fluoro- } N \text {-acetylhexosamine } \\
\text { pyruvate }\end{array}$ & $\begin{array}{l}N \text {-acyl-D-glucosamine 2-epimerase } \\
\text { sialic acid aldolase } \\
\text { CMP sialic acid synthetase } \\
\text { inorganic pyrophosphatase } \\
\text { sialyltransferase }\end{array}$ & $(7 \mathrm{~F}-)$ sialyl galactoside \\
\hline
\end{tabular}


ions, inhibition of other enzymes by intermediate products or coenzymes). Finally, it is necessary to balance the activity and stability of multiple enzymes at the same time.

\section{Structure and catalytic mechanism of fluorinases}

As an important biocatalyst for the formation of the C-F bond, the structure and catalytic mechanism of fluorinase have always been a topic of concern in the field of biocatalysis and biotransformation. There is a close relationship between protein structure and function. Therefore, studying the structure of fluorinase is essential for understanding the catalytic mechanism of enzymes. To confirm the conserved amino acids, the multiple sequence alignment of six known fluorinases was constructed using DNAMAN (Figure S14). 182 conserved residues were identified, and the identity is as high as $85.11 \%$. This indicated that the six known fluorinases have a high degree of homology and evolutionary origin from the primary structure of the protein. These conserved regions are the key to the catalytic function of fluorinases. Moreover, the crystal structures of fluorinases have been obtained only from two microbial sources, Streptomyces cattleya, and Streptomyces sp. MA37. The first crystal structure of fluorinase from $S$. cattleya was resolved to $1.9 \AA$ A resolution (Cobb et al. 2006; Dong et al. 2003, 2004). Through gel filtration analysis, the single frozen protein is a symmetrical hexamer $(186 \mathrm{kDa})$ composed of two trimers. The trimer is composed of three identical monomers (Fig. 9A). The monomer has two domains: the amino-terminal domain (residues 1-180) and the carboxyterminal domain (residues 195-298), and a loop structure that connects the two domains (residues 181-194) (Fig. 9B). The amino-terminal domain is composed of two antiparallel $\beta$-sheets with 4 and 5 helices. The carboxy-terminal domain has a 7 -stranded $\beta$-sheet, which is sandwiched between the parallel and antiparallel $\alpha$-helix strands. However, a single crystal structure cannot completely analyze the catalytic mechanism of fluorinase. As such, the crystal structure of fluorinase bound to substrate and product was obtained (Fig. 9C). In this structure, SAM was located between the C-terminal of a monomer and the N-terminal of a monomer in the trimer (Fig. 9D). The catalytic function of fluorinase must rely on the interactions of two monomers. As shown in Fig. 9E and F, the active sites of the fluorinase are distributed around the substrates or products and at the ends of two adjacent monomers. When combined, SAM is completely buried by fluorinase, which suggests that the fluorinase has other open conformations during the catalysis process. Comparing the binding status of substrate and product with fluorinase showed that 5'-FDA and L-methionine occupied the binding site of SAM after the reaction. Also, the difference between the two states is very small except for the bond formation/fracture area (Deng et al. 2004). This indicates that the key structures and regions are similar to the substrates and products of fluorinase and located between the two domains. Furthermore, the reaction is activated by changes in these key structures and regions.

In the field of organic chemistry, $\mathrm{S}_{\mathrm{N}} 2$ nucleophilic substitution is a paradigm reaction (Xie and Hase 2016). Through structure and function analysis, asymmetric $\mathrm{S}_{\mathrm{N}} 2$ nucleophilic fluorination is the key to the formation of C-F bonds for fluorinase (Pupo et al. 2018). Moreover, the $\mathrm{S}_{\mathrm{N}} 2$ reaction mechanism of fluorinase was also supported strongly by QM/MM calculations (Senn et al. 2005). In the process of forming the C-F bond, the reaction is thermodynamically driven due to the slow reaction $K_{\text {cat }}$ and the equilibrium of the reaction lies in the products. The $\mathrm{S}_{\mathrm{N}} 2$ nucleophilic attack will provide a hydrogen bond for the anion, which can stabilize the desolvated $\mathrm{F}^{-}$and is very important for the selective fluorination of $s p^{3}$ carbon centers (Lee et al. 2016). This indicates that the positively charged SAM sulfur is a crucial factor in stabilizing the partial desolvation and transition state. Consequently, the detailed molecular mechanism of fluorinase was further revealed (Zhu et al. 2007). During the catalysis process, solvated fluorine first binds to the unoccupied pockets and exchanges the hydrogen bonds of the water molecules to the polar groups of the protein (amide $\mathrm{NH}$ and side-chain $\mathrm{OH}$ of S158). The SAM is then bound, and the remaining water molecules enter the hydrophobic binding pocket to dissociate the fluorine. Remarkably, SAM is a competitive inhibitor of fluoride ion binding to fluorinase during the transition state. Afterwards, fluorine $\mathrm{S}_{\mathrm{N}} 2$ attacks C5 of SAM and replaces L-Met of SAM. After the conformation of loop (A95-Q102) changes, L-Met is released. Moreover, the loop participates in the combination of L-Met but not directly combined with L-Met. And then, the conformation of a loop (T75-R85) is changed to release 5'-FDA, which the loop forms the binding region for the adenine ring and ribose of SAM and 5'-FDA derivatives.

To further explore the catalytic mechanism of fluorinases, a series of different types of substrates and mutants were analyzed and compared. When analyzing the crystal structure of fluorinase, an extensive hydrogen bond network was formed through water molecules and the carboxylate groups of L-Met with amino acids (T155, W217, Y266, backbone amide of S269) (Thomsen et al. 2013). The two water molecules were tightly bound at the active site of the fluorinase. This indicated that the instability of these water molecules may promote the accommodation of sterically bulky substrates. Therefore, site-directed mutagenesis was performed at these sites by introducing small hindered amino acids and disrupting the hydrogen bond network. Y266F and T155S exhibited significantly higher catalytic efficiency than that of the wild type. The results showed that the hydrogen bond network of the active center is an important factor for fluorinase to accommodate large sterically hindered substrates. 
Fig. 9 The structures of fluorinase. A) The trimer structure formed by three monomers; B) The monomer structure formed by the amino-terminal domain (blue), carboxy-terminal domain (yellow), and loop linker (red); C) The co-crystal structure of trimer and substrate SAMs; The SAM molecules are displayed in CPK format; $\mathbf{D})$ The stereogram of SAM, fluorine (Replaced by chlorine in actual experiments) and interacting monomers during the catalysis process; E) The three-dimensional structure of the substrates and active sites complex; The SAM is displayed as a stick model with center carbon in blue; The fluorine is displayed in light blue; F) The three-dimensional structure of the products and active sites complex; The 5'-FDA and L-Met are displayed as a stick model with center carbon in blue. Note: Classical hydrogen bond: green dashed line; Non-classical hydrogen bond: gray dashed line; Electrostatic interaction: orange dashed line; Hydrophobic interaction: purple dashed line
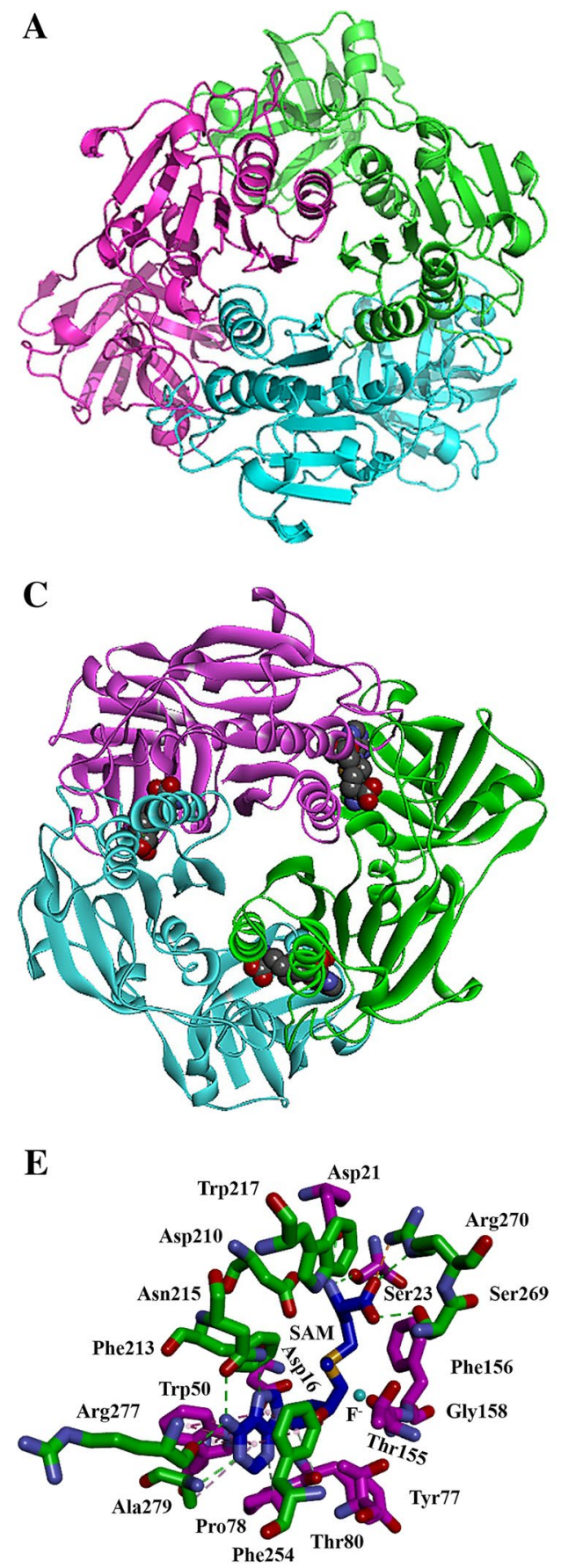
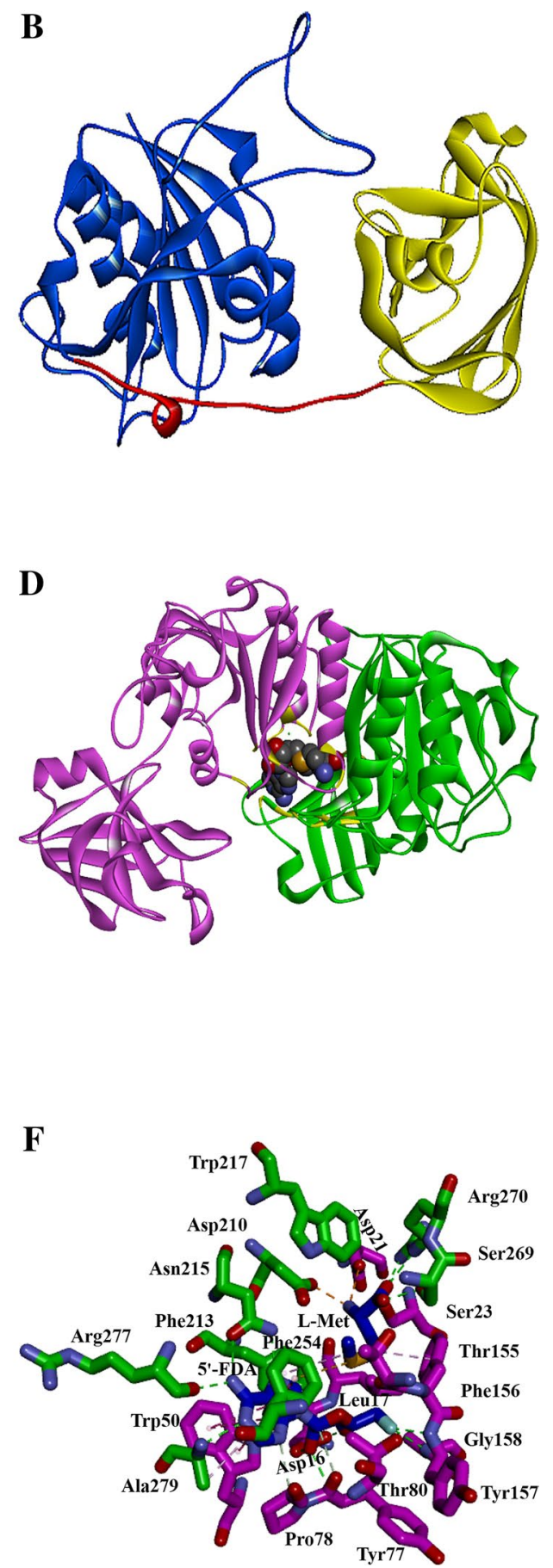

The two amino acid residues 266 and 155 play a significant role in the formation of the hydrogen bond network. For substrates modified at the $\mathrm{C} 2\left(\mathrm{R}_{1}\right.$ substitution) and $\mathrm{C} 6\left(\mathrm{R}_{2}\right.$ substitution) positions of the adenine ring, the substrates catalytic range was also studied (Figure S15) (Yeo et al. 2017). The results showed that substrates with hydrogen donors at the $\mathrm{C} 2$ position of the adenine group interact better with the fluorinase, obtaining a high yield. Besides, amino acid residue 279 plays an important role in promoting binding to ethynyl of the substrate at the $\mathrm{C} 2$ position. The $\mathrm{C} 2$ position is sensitive to large steric hindrances. Unfortunately, all substitutions at the $\mathrm{C} 6$ position caused catalysis difficulties, except for chlorine and hydrogen. Similarly, the directed evolution was also implemented in the process of catalyzing 5'-CIDA to SAM to 5'-FAD (Sun et al. 2016). Mutants F213Y/A279L have been shown to increase the yield of 5'-FDA. Specifically, F213Y/A279L can increase the turnover from $5^{\prime}$-CIDA to SAM but decrease the turnover from 
SAM to $5^{\prime}$-FAD. These mutations did not affect the affinity of the enzyme to $5^{\prime}$-CIDA but increase the affinity to SAM. The movement of the loop (277-281) is closely related to the binding of fluorinase and adenine. When position 279 is mutated to a large hindered amino acid, the movement of the loop is restricted, resulting in a tighter binding. Moreover, the hydrophobic environment facilitates the binding of substrates in the substrate-binding pocket. Leu279 and Tyr213 participate in favorable hydrophobic contact. The former improves the hydrophobicity of the environment through van der Waals forces with aromatic carbon of adenosine. The latter acts as a clamp between protein monomers across the ribose ring. Additionally, the reverse reaction of fluorinase was also applied to study the catalytic mechanism of the substrate with the difluoromethyl group (Thompson et al. 2016b). Regrettably, no reaction was observed in the presence of 5',5'-difluoro-5'-deoxyadenosine $7\left(\mathrm{~F}_{2} \mathrm{DA}\right)$ and L-Met/L-SeMet. As such, the co-crystal structure of fluorinase and $\mathrm{F}_{2} \mathrm{DA}$, and tartrate was obtained to analyze the reason $(1.8 \AA)$. Structural analysis showed that the difluoromethyl bridged the interaction known to be essential for the activation of single fluorine in $5^{\prime}$-FDA. The bridging reaction was combined with the strong $\mathrm{C}-\mathrm{F}$ bonds inherent in the difluoromethyl group, and there was an abnormal hydrogen bond interaction between the hydrogen of the difluoromethyl group and hydroxyl oxygen of the tartrate ligand. This indicated that the geometry of the bond is no longer suitable for the attack of sulfur or selenium and form higher response barriers. This explains why no response was observed for $\mathrm{F}_{2} \mathrm{DA}$. Thus, the hydrophobic environment and steric hindrance of the substrate-binding pocket are essential for the catalytic reaction of fluorinase. In addition, the movement of the loop structure is also essential to regulating the catalytic function around the substrate binding pocket.

\section{Applications of fluorinated compounds}

\section{PET tracers}

Positron emission tomography (PET) is a non-invasive molecular imaging technique that relies on compounds labeled with positron emitters (da Silva et al. 2018; Preshlock et al. 2016). Nowadays, PET has become a valuable tool for detecting pathology in the clinical field. Fluorine is a typical positron emitter due to its long half-life $\left(\mathrm{t}_{1 / 2}=110 \mathrm{~min}\right)$, high isotope abundance, large gyromagnetic ratio, sensitivity, and specificity (Clark and O'Hagan 2017; da Silva et al. 2018; Lu et al. 2019; Troelsen et al. 2020; Yamamoto et al. 2019). Since 2-fluorinated glycosides are more stable than glycosides, they can be used as active probes (Sadurni and Gilmour 2018). In traditional PET technology, $2-{ }^{18}$ F-fluoro-2-deoxy-D-glucose $\left({ }^{18}\right.$ F-FDG) was the most commonly used tracer in the diagnosis of most diseases. Nevertheless, ${ }^{18} \mathrm{~F}$-FDG-PET is far from meeting the requirements of modern disease detection technology. ${ }^{18}$ F-FDG is based on glucose, but most disease tissues contain a lot of glucose which interfere with accuracy (de Zwart et al. 2020; Langen et al. 2017; Lohmann et al. 2019). Therefore, more and more fluorinated PET tracers are being developed. For example, the ${ }^{18} \mathrm{~F}$-fluoro-L-3,4dihydroxy-phenylalanine $\left({ }^{18} \mathrm{~F}-\mathrm{DOPA}\right)$ was used as an amino acid tracer in PET imaging (Christine et al. 2019; Fraioli et al. 2020; Mossine et al. 2020). This $\left({ }^{18} \mathrm{~F}\right.$-DOPA) PET could be applied to assess the volume of remaining gliomas in the patient, Parkinson's syndrome, and focal hyperinsulinemia in infants, which was a perfect complement to the traditional detection technology. Except that, other types of fluorinated compounds were also used as PET tracers for cancer and tumor detection, such as ${ }^{18} \mathrm{~F}$-PSMA-1007 (Dietlein et al. 2020), L-2 $-{ }^{18}$ F-FAMP, D-2/3/4- ${ }^{18}$ F-FAMP and L-3- ${ }^{18}$ F-FAMT (Hanaoka et al. 2019; Mahendra et al. 2020; Shimizu et al. 2019), $\left({ }^{18} \mathrm{~F}-\mathrm{FBPA}\right)$ (Romanov et al. 2020), ${ }^{18}$ F-fluoro-ethyl-L-tyrosine $\left({ }^{18} \mathrm{~F}\right.$-FET) (Fuenfgeld et al. 2020; Marner et al. 2019), 6- ${ }^{18}$ F-fluoro-meta-tyrosine $\left({ }^{18}\right.$ F-FMT) (Badin et al. 2019; Kojima et al. 2019; Miyamoto et al. 2020), $N-\left[{ }^{18} \mathrm{~F}\right]$-fluoropropylJDTic (Schmitt et al. 2017), 2-(3-(1-carboxy-5-[(6- ${ }^{18} \mathrm{~F}$-fluoro-pyridine-3-carbonyl)amino]-pentyl)-ureido)-pentanedioic acid ( ${ }^{18} \mathrm{~F}$-DCFPyL) (Jansen et al. 2019; Rousseau et al. 2019; Rowe et al. 2020a, 2020b), $5-{ }^{18} \mathrm{~F}$-fluoro-L-amino suberate $\left({ }^{18} \mathrm{~F}-\mathrm{FASu}\right.$ ) (Alluri et al. 2020; Colovic et al. 2019), 4-borono-2- ${ }^{18} \mathrm{~F}$-fluoroL-phenylalanine fluorine substituted 3-azabicyclo hexane (Chen et al. 2019b), and $\left[{ }^{18}\right.$ F]FDA-PEG-biotin/tetrazine (Lowe et al. 2018). Therefore, PET tracers based on new fluorinated compounds will play an increasing role in the field of visual detection technology.

\section{Antitumor inhibitors}

To effectively treat the tumor, inhibiting key enzymes of tumor cells is regarded as an important treatment. Hence, many fluorinated compounds have been developed as novel antitumor inhibitors, considering the problems of drug resistance, solubility, and toxicity. For example, diverse fluorinated cyclohexene derivatives were used to inhibit the activity of hOAT to treat HCC, because human ornithine aminotransferase (hOAT) plays an essential role in metabolic pathways of hepatocellular carcinoma (HCC) (Zhu et al. 2020b). Especially $(1 R, 3 S, 4 S)$-3-amino-4,4-difluoro cyclopentane-1-ene-1-carboxylate and $(1 R, 3 S, 4 S)$-3-amino4-fluoro cyclopentane-1-ene-1-carboxylate, they showed the total different inactivation mechanisms from previous inhibitors. Moreover, tyrosine kinase (TK) is the epidermal growth factor receptor (EGFR) of A549 and Hela cancer cells. Four fluorinated quinazolinone derivatives showed 
excellent anti-proliferative properties against A549 and Hela cancer cells by inhibiting TK $\left(\mathrm{IC}_{50}=0.462-7.568 \mu \mathrm{M}\right.$; $\left.\mathrm{IC}_{50}=0.175-7.096 \mu \mathrm{M}\right)$ (Le et al. 2020).

In addition to better resistance, fluorine-containing inhibitors have a stronger inhibitory effect than traditional non-fluorine anti-tumor inhibitors. Such as, steroid sulfatase (STS) is an important enzyme to regulate metabolism in breast cancer cells, which is a malignant tumor with the highest incidence among women (Armstrong et al. 2020; Maltais et al. 2020). Therefore, various inhibitors of STS have been developed gradually. To improve the inhibitory effect, C-F bonds were introduced into STS inhibitors. Their inhibitory efficacy was ten-fold that of traditional inhibitor (coumarin-7-O-sulfamate), especially 3-(3,4-difluorophenyl)-2-oxo-2 $H$-chromen-7-yl sulfamate, 2-oxo-3-(3,4,5-trifluorophenyl)-2H-chromen-7-yl sulfamate, 3-(2-(2,5-bis(trifluoromethyl)phenyl)acetamido)-2-oxo- $2 \mathrm{H}$ chromen-7-yl sulfamate, and 3-(3,4-difluorobenzamido)2-oxo- $2 H$-chromen-7-yl sulfamate $\left(\mathrm{IC}_{50}=0.18-0.27 \mu \mathrm{M}\right)$ (Dasko et al. 2017; Demkowicz et al. 2016). Correspondingly, tautomerase is human macrophage migration inhibitory factor (MIF), which is also a pro-inflammatory cytokine associated with many tumors. Studies showed that the growth of the tumor can be effectively inhibited by MIF inhibitors and the inhibitory effect can be significantly enhanced by adding fluorine atoms (Dziedzic et al. 2015). Similarly, other fluorinated compounds also exhibited stronger inhibitory effects than non-fluorinated compounds for distinct tumor cells, such as fluorinated green tea polyphenols, fluorinated largazole, fluorinated 4-thiazolidinone, fluorinated griseofulvin, fluorinated L-threonine, fluorinated aminophosphonite, and fluorinated docetaxel (Zhang et al. 2019a) (Stadlbauer et al. 2018) (Makki et al. 2019; Olgun 2019; Paguigan et al. 2017; Sudileti et al. 2019; Tang et al. 2016). These results indicated that the incorporation of fluorine-substituted fragments into the inhibitor is an effective means to enhance the therapeutic effect of tumors.

\section{Antiviral inhibitors}

In addition to being novel anti-tumor inhibitors, fluorinated compounds are also effective against viruses. Coxsackie virus $\mathrm{B}$ (CVB) is a common pathogen for humans, causing aseptic meningitis, pericarditis, and myocarditis. To counter CVB, seven fluorinated pyrimidine nucleoside analogs were synthesized and tested for their antiviral activity (Tao et al. 2020). The results showed that $4-N-\left(2^{\prime}\right.$-aminoglutarate-1'-methylester)-1-(2'-deoxy-2'- $\beta$-fluoro-4'-azido)furanosyl-cytosine has the most effective activity of antiCVB $\left(\mathrm{IC}_{50}=9.3 \mu \mathrm{M}\right)$. Similarly, 1-(2'-Deoxy-2'-fluoro- $\beta$-D -arabinofuranosyl)benzimidazoles were also proven to have anti-herpes virus activity (Kharitonova et al. 2016). As for antiviral activity, the global health system is currently being destroyed by the novel coronavirus (COVID-19). Although diverse vaccines have been developed, they cannot produce a therapeutic effect on patients who have been infected with COVID-19. As such, it is crucial to find special drugs for COVID-19. As we all know, protease $\mathrm{M}^{\text {pro }}$ is an important drug target for COVID-19. Through molecular simulation, antiviral $N$-heterocycles (2'-fluoro-2'-deoxycytidine) was evaluated for its inhibitory effect on protease and showed good affinity for target receptors (Hagar et al. 2020). So far, there is no specific drug that can treat COVID-19 through experimental verification. But, it is believed that fluorinated compounds have this potential. Moreover, more and more fluorinted compounds will be artificially synthesized and used to fight viruses in the future of fluorinated biochemistry.

\section{Pharmaceutical intermediates}

Traditional pharmaceutical intermediates are increasingly unable to meet the needs of the current pharmaceutical industry. The development of novel pharmaceutical intermediates has become more and more urgent and necessary. Selective fluorination is an effective strategy to improve pharmaceutical efficacy, half-life, lipophilicity, absorption rate, and the permeability of cell membranes (Sudileti et al. 2019; Zhou et al. 2016). Therefore, the exploration has never stopped for the role of fluorine in drug design since the first fluorinated drug ( $9 \alpha$-fluoro-substituted corticosteroid fludrocortisone) was approved in the 1950s (Fried and Sabo 1954). Nowadays, fluorine functional groups are contained in more than $25-30 \%$ of drugs, such as mefloquine, teriflunomide, citalopram, sorafenib, efavirenz, tedizolid phosphate, donepezil, and vorapaxar (Adler et al. 2019; Izquierdo et al. 2019; Khosravan et al. 2017; Markakis et al. 2020; Mei et al. 2019, 2020b; Palmer-Brown et al. 2017; Zhang et al. 2020b).

A typical example is the use of fluorinated compounds as drug intermediates for the treatment of Alzheimer's disease (AD). $\mathrm{AD}$ is associated with changes in cAMP (cyclic adenosine monophosphate) and cGMP (cyclic guanosine monophosphate) signals (Nakashima et al. 2019). Accordingly, regulating the levels of cAMP and cGMP in the brain has become an effective means of treating AD. It is known that phosphodiesterase 2A (PDE2A) is involved in the hydrolysis of cAMP and cGMP. Therefore, fluorine-substituted carboxamide analog as PDE2A inhibitors (TAK915) was used to test the effect of treating AD. The results showed that TAK-915 was the most effective in treating AD when taken orally at $10 \mathrm{mg} / \mathrm{kg}$. In addition, acetylcholinesterase is also an important target of AD. The activity of acetylcholinesterase can be inhibited by piperine. To overcome the poor water solubility and photostability of piperine, a threo-difluoropiperine analog was synthesized and showed higher potency and selectivity than piperine for the treatment of AD (Lizarme-Salas et al. 2020). Similarly, 
fluorinated compounds are also the key building blocks of antibiotic, antimalarial, antiinflammatory, asthma, antagonists, migraine, and central nervous system drugs, such as 2,2-bis(6-fluoro-1H-indol-3-yl)ethan-1-amine, fluorinated steroidal, Trifluorothymidine and fluorouracil polytoxin, fluorinated cholesterol, fluorinated galegine, fluorinated bastimolide A, 6(R/S)-fluoropenibruguieramine, fluorinated cyclopropanecarboxylic acid derivatives, aryl-fluoro sulfates, 3-fluoro-4-aminopiperidine, and $\beta$-fluoramines (Adler et al. 2019; Bakhotmah and Abdel-Rahman 2017; Campana et al. 2020; Frank et al. 2016; Fujino et al. 2017; Gambini et al. 2019; Liu et al. 2018; Molinaro et al. 2019; Munck Af Rosenschold et al. 2019; Pupo et al. 2019; Quintard et al. 2018; Shao et al. 2015; Wu et al. 2020d). Accordingly, fluorinated compounds will pay more and more attention to the research and development of new pharmaceutical intermediates. Many intractable diseases are also expected to be cured.

\section{Functional materials}

As we all know, white spot lesion (WSL) is the main cause of dental caries. The main measure of WSL management is to prevent the formation of new lesions. The fluorinated compounds can harden the surface layer of minerals, thereby preventing the occurrence of lesions and the development of dental caries (Decha et al. 2019; Lena Sezici et al. 2021; Raskin et al. 2021; Shah et al. 2018). Therefore, fluorinated compounds can be used to synthesize dental care materials, especially silver diamine fluoride, quaternary ammonium fluoride salt. Besides, the fluorinated membrane also displayed anti-pollution and anti-wetting properties in the field of industrial wastewater treatment (Abdulkarem et al. 2021; Cheng et al. 2021; Ji et al. 2021; Kang et al. 2021; Koh and Lee 2021; Li et al. 2021; Nayak and Tripathi 2021; Xiao et al. 2021; Zhong et al. 2021). Due to this unique performance, the fluorinated membrane can be used to treat wastewater with high salinity and hardness, remove heavy metal ions, separate oil, water, and as a flexible dielectric material and air filter with antibacterial properties. Moreover, the performance of traditional materials can also be enhanced by fluorine substitution. For instance, acrylate is the main component of rubber; Fluorinated acrylate is usually used to improve the compatibility and toughness of rubber (Yimmut et al. 2018). Similarly, fluorographene is a two-dimensional material with a high surface-to-mass ratio. Unlike graphene, fluorographene material is a wide band gap insulator because it lacks a conjugated network of $\pi$-conjugated electrons. As one of the thinnest insulators, fluorographene is most commonly used in the battery field. Fluorographene also plays an important role in industrial lubrication due to its delamination nature, low surface energy, and easy peeling characteristics (Chronopoulos et al. 2017; Liang et al. 2021). As such, fluorinated compounds are gradually becoming important sources of novel functional materials.

\section{Conclusions and perspectives}

Fluorine is a distinctive element and fluorine-containing organic compounds are playing an increasingly important role in the fields of molecular imaging, pharmaceuticals, and materials. This has also led to high demand for reagents capable of selectively introducing fluorine into organics, especially biological enzyme catalysts. In this review, 13 enzymatic pathways are introduced. There are two main strategies for the enzymatic synthesis of fluorinated compounds: (1) C-F bonds are directly formed to obtain fluorine-containing compounds. (2) Complex fluorinated compounds are synthesized from simple fluorinecontaining modules. Of all the current enzymatic methods, the catalytic route mediated by fluorinase has the most potential for applications. Nevertheless, the artificial green synthesis of fluorinated compounds still has a long way to go. Since C-F is a strong and inert chemical bond, it is extremely challenging to artificially synthesize compounds containing the C-F bond, especially the selective incorporation of fluorine into biologically active molecules.

Therefore, many future efforts will be made by our laboratory and other counterparts in the following aspects. (I) More and more new fluorinated natural products will be discovered and their biosynthetic pathways will be explored. Based on these biosynthetic pathways, artificial synthetic systems will be reconstructed to synthesize fluorinated natural products and their analogs. (II) Directed evolution based on machine learning is a mainstream tool for fluorinase, which will improve the efficiency and range of fluoride synthesis. Through this process, fluorinated nucleoside derivatives and non-nucleoside fluorides will have the opportunity to be obtained. (III) New enzymes that can directly form C-F bonds will be identified through metagenomics and gene mining methods. At that time, various fluorinated organic compounds will be easily obtained by direct fluorination at different positions and different groups. (IV) To introduce fluorine into valuable natural products, fluorine-containing building blocks will be introduced into complex natural product biosynthesis pathways through in vivo and in vitro synthetic biology methods. Besides, the toxicity of fluorides will also be overcome for synthetic biology in vivo based on the understanding of the mechanism of fluoride detoxification and detoxification of organisms.

Supplementary Information The online version contains supplementary material available at https://doi.org/10.1007/s00253-021-11608-0. 
Author contribution XC collected literature data, conceived the idea and wrote the manuscript. LM conceived the idea and revised the manuscript. All authors read and approved the final version of the paper.

Funding This work was financially supported by the National Natural Science Foundation of China (No. 21672161), Tianjin Municipal Science and Technology Commission (18PTSYJC00140), State Key Laboratory of Food Nutrition and Safety, Tianjin University of Science \& Technology (19PTSYJC00060), Scientific Research Project of Tianjin Education Commission (2019KJ239).

\section{Declarations}

Ethics approval This article does not contain any studies with human participants or animals performed by any of the authors.

Conflict of interest The authors declare no competing interests.

\section{References}

Abdulkarem E, Ibrahim Y, Kumar M, Arafat HA, Naddeo V, Banat F, Hasan SW (2021) Polyvinylidene fluoride (PVDF)-alpha-zirconium phosphate (alpha-ZrP) nanoparticles based mixed matrix membranes for removal of heavy metal ions. Chemosphere 267:128896. https://doi.org/10.1016/j.chemosphere.2020.128896

Ad O, Thuronyi BW, Chang MC (2017) Elucidating the mechanism of fluorinated extender unit loading for improved production of fluorine-containing polyketides. Proc Natl Acad Sci U S A 114(5):E660-E668. https://doi.org/10.1073/pnas.1614196114

Adler P, Teskey CJ, Kaiser D, Holy M, Sitte HH, Maulide N (2019) $\alpha$-Fluorination of carbonyls with nucleophilic fluorine. Nat Chem 11(4):329-334. https://doi.org/10.1038/s41557-019-0215-z

Adrover-Castellano ML, Schmidt JJ, Sherman DH (2021) Biosynthetic cyclization catalysts for the assembly of peptide and polyketide natural products. ChemCatChem 13(9):2095-2116. https://doi. org/10.1002/cctc. 202001886

Aleku GA, France SP, Man H, Mangas-Sanchez J, Montgomery SL, Sharma M, Leipold F, Hussain S, Grogan G, Turner NJ (2017) A reductive aminase from Aspergillus oryzae. Nat Chem 9(10):961-969. https://doi.org/10.1038/nchem.2782

Alluri SR, Pitman KE, Malinen E, Riss PJ (2020) Synthesis, radiosynthesis, and positron emission tomography neuroimaging using 5- $\left[{ }^{18} \mathrm{~F}\right]$ fluoro-L-amino suberate. J Labelled Comp Radiopharm 63(1):6-14. https://doi.org/10.1002/jlcr.3814

Arias M, Aramini JM, Riopel ND, Vogel HJ (2020) Fluorine-19 NMR spectroscopy of fluorinated analogs of tritrpticin highlights a distinct role for Tyr residues in antimicrobial peptides. Biochim Biophys Acta Biomembr 1862(6):183260. https://doi.org/10. 1016/j.bbamem.2020.183260

Armstrong CM, Liu C, Liu L, Yang JC, Lou W, Zhao R, Ning S, Lombard AP, Zhao J, D’Abronzo LS, Evans CP, Li PK, Gao AC (2020) Steroid sulfatase stimulates intracrine androgen synthesis and is a therapeutic target for advanced prostate cancer. Clin Cancer Res 26(22):6064-6074. https://doi.org/10.1158/10780432.CCR-20-1682

Awad LF, Ayoup MS (2020) Fluorinated phenylalanines: synthesis and pharmaceutical applications. Beilstein J Org Chem 16:1022_ 1050. https://doi.org/10.3762/bjoc.16.91

Badin RA, Binley K, Van Camp N, Jan C, Gourlay J, Robert C, Gipchtein P, Fayard A, Stewart H, Ralph GS, Lad Y, Kelleher M, Loader J, Hosomi K, Palfi S, Mitrophanous KA, Hantraye P (2019) Gene therapy for parkinson's disease: Preclinical evaluation of optimally configured TH:CH1 fusion for maximal dopamine synthesis. Mol Ther Methods Clin Dev 14:206-216. https://doi.org/10.1016/j.omtm.2019.07.002

Bakhotmah D, Abdel-Rahman R (2017) Synthesis and structural determination of novel fluorinated steroidal spiro(pyrazolo[4,3e] $[1,2,4]$ triazin-3'-yl) derivatives as affecting enzymatic agents. Lett Org Chem 14(2):134-140. https://doi.org/10.2174/ 1570178614666161230143228

Bentler P, Bergander K, Daniliuc CG, Muck-Lichtenfeld C, Jumde RP, Hirsch AKH, Gilmour R (2019) Inverting small moleculeprotein recognition by the fluorine gauche effect: Selectivity regulated by multiple $\mathrm{H} \rightarrow \mathrm{F}$ bioisosterism. Angew Chem Int Ed Engl 58(32):10990-10994. https://doi.org/10.1002/anie. 201905452

Bucci R, Contini A, Clerici F, Beccalli EM, Formaggio F, Maffucci I, Pellegrino S, Gelmi ML (2019) Fluoro-aryl substituted alpha, beta(2,3)-peptides in the development of foldameric antiparallel beta-sheets: A conformational study. Front Chem 7:192. https:// doi.org/10.3389/fchem.2019.00192

Busto E, Gerstmann M, Tobola F, Dittmann E, Wiltschi B, Kroutil W (2016) Systems biocatalysis: para-alkenylation of unprotected phenols. Catal Sci Technol 6(22):8098-8103. https://doi.org/10. 1039/c6cy01947a

Calero P, Volke DC, Lowe PT, Gotfredsen CH, O'Hagan D, Nikel PI (2020) A fluoride-responsive genetic circuit enables in vivo biofluorination in engineered Pseudomonas putida. Nat Commun 11(1):5045. https://doi.org/10.1038/s41467-020-18813-x

Campana R, Mangiaterra G, Tiboni M, Frangipani E, Biavasco F, Lucarini S, Citterio B (2020) A fluorinated analogue of marine bisindole alkaloid 2,2-bis(6-bromo-1H-indol-3-yl)ethanamine as potential anti-biofilm agent and antibiotic adjuvant against Staphylococcus aureus. Pharmaceuticals (basel) 13(9):210. https://doi. org/10.3390/ph13090210

Carvalho MF, Oliveira RS (2017) Natural production of fluorinated compounds and biotechnological prospects of the fluorinase enzyme. Crit Rev Biotechnol 37(7):880-897. https://doi.org/10. 1080/07388551.2016.1267109

Cavalcante FTT, Neto FS, de Aguiar R, Falcão I, da Silva E, Souza J, de Moura Junior LS, da Silva SP, Rocha TG, de Sousa IG, de Lima Gomes PH, de Souza MCM, dos Santos JCS (2021) Opportunities for improving biodiesel production via lipase catalysis. Fuel 288:119577. https://doi.org/10.1016/j.fuel.2020.119577

Chen K, Arnold FH (2020) Engineering new catalytic activities in enzymes. Nat Catal. https://doi.org/10.1038/s41929-019-0385-5

Chen Q, Chen X, Cui Y, Ren J, Lu W, Feng J, Wu Q, Zhu D (2017) A new D-threonine aldolase as a promising biocatalyst for highly stereoselective preparation of chiral aromatic $\beta$-hydroxy- $\alpha$-amino acids. Catal Sci Technol 7(24):5964-5973. https://doi.org/10. 1039/c7cy01774j

Chen Q, Chen X, Feng J, Wu Q, Zhu D, Ma Y (2019a) Improving and inverting $C \beta$-stereoselectivity of threonine aldolase via substratebinding-guided mutagenesis and a stepwise visual screening. ACS Catal 9(5):4462-4469. https://doi.org/10.1021/acscatal. 9b00859

Chen Z, Mori W, Fu H, Schafroth MA, Hatori A, Shao T, Zhang G, Van RS, Zhang Y, Hu K, Fujinaga M, Wang L, Belov V, Ogasawara D, Giffenig P, Deng X, Rong J, Yu Q, Zhang X, Papisov MI, Shao Y, Collier TL, Ma JA, Cravatt BF, Josephson L, Zhang MR, Liang SH (2019b) Design, synthesis, and evaluation of ${ }^{18}$ F-labeled monoacylglycerol lipase inhibitors as novel positron emission tomography probes. J Med Chem 62(19):8866-8872. https://doi.org/10.1021/acs.jmedchem.9b00936

Cheng L, Sun H, Xu J, Yu C, Xiao H, Wang R, Xu L, Zeng Z, Liang S (2021) Emulation of synaptic behavior by organic ferroelectric tunnel junctions. Phys Lett A 392:127138. https://doi.org/10. 1016/j.physleta.2021.127138 
Christine CW, Bankiewicz KS, Van Laar AD, Richardson RM, Ravina B, Kells AP, Boot B, Martin AJ, Nutt J, Thompson ME, Larson PS (2019) Magnetic resonance imaging-guided phase 1 trial of putaminal AADC gene therapy for Parkinson's disease. Ann Neurol 85(5):704-714. https://doi.org/10.1002/ana.25450

Chronopoulos DD, Bakandritsos A, Pykal M, Zboril R, Otyepka M (2017) Chemistry, properties, and applications of fluorographene. Appl Mater Today 9:60-70. https://doi.org/10.1016/j. apmt.2017.05.004

Clark J, O'Hagan D (2017) Strategies for radiolabelling antibody, antibody fragments and affibodies with fluorine-18 as tracers for positron emission tomography (PET). J Fluorine Chem 203:31-46. https://doi.org/10.1016/j.jfluchem.2017.08.001

Cobb SL, Deng H, McEwan AR, Naismith JH, O'Hagan D, Robinson DA (2006) Substrate specificity in enzymatic fluorination. The fluorinase from Streptomyces cattleya accepts 2 '-deoxyadenosine substrates. Org Biomol Chem 4(8):1458. https://doi.org/10.1039/ b600574h

Colovic M, Yang H, Merkens H, Colpo N, Benard F, Schaffer P (2019) The effect of chirality on the application of $5-\left[{ }^{18} \mathrm{~F}\right]$ fluoro-aminosuberic acid $\left(\left[{ }^{18} \mathrm{~F}\right] \mathrm{FASu}\right)$ for oxidative stress imaging. Mol Imaging Biol. https://doi.org/10.1007/s11307-019-01450-2

Council CE, Kilpin KJ, Gusthart JS, Allman SA, Linclau B, Lee SS (2020) Enzymatic glycosylation involving fluorinated carbohydrates. Org Biomol Chem 18(18):3423-3451. https://doi.org/10. 1039/d0ob00436g

Cuetos A, Garcia-Ramos M, Fischereder EM, Diaz-Rodriguez A, Grogan G, Gotor V, Kroutil W, Lavandera I (2016) Catalytic promiscuity of transaminases: Preparation of enantioenriched beta-fluoroamines by formal tandem hydrodefluorination/deamination. Angew Chem Int Ed Engl 55(9):3144-3147. https://doi. org/10.1002/anie.201510554

da Silva ES, Gomez-Vallejo V, Lopez-Gallego F, Llop J (2018) Biocatalysis in radiochemistry: Enzymatic incorporation of PET radionuclides into molecules of biomedical interest. J Labelled Comp Radiopharm 61(4):332-354. https://doi.org/10.1002/jlcr.3592

Dasko M, Przybylowska M, Rachon J, Maslyk M, Kubinski K, Misiak M, Skladanowski A, Demkowicz S (2017) Synthesis and biological evaluation of fluorinated N-benzoyl and N-phenylacetoyl derivatives of 3-(4-aminophenyl)-coumarin-7-O-sulfamate as steroid sulfatase inhibitors. Eur J Med Chem 128:79-87. https:// doi.org/10.1016/j.ejmech.2017.01.028

de Zwart PL, van Dijken BRJ, Holtman GA, Stormezand GN, Dierckx R, Jan van Laar P, van der Hoorn A (2020) Diagnostic accuracy of PET tracers for the differentiation of tumor progression from treatment-related changes in high-grade glioma: A systematic review and metaanalysis. J Nucl Med 61(4):498-504. https://doi. org/10.2967/jnumed.119.233809

Decha N, Talungchit S, Iawsipo P, Pikulngam A, Saiprasert P, Tansakul C (2019) Synthesis and characterization of new hydrolyticresistant dental resin adhesive monomer HMTAF. Des Monomers Polym 22(1):106-113. https://doi.org/10.1080/15685551. 2019.1615789

Demkowicz S, Dasko M, Kozak W, Krawczyk K, Witt D, Maslyk M, Kubinski K, Rachon J (2016) Synthesis and biological evaluation of fluorinated 3-phenylcoumarin-7-O-sulfamate derivatives as steroid sulfatase inhibitors. Chem Biol Drug Des 87(2):233-238. https://doi.org/10.1111/cbdd.12652

Deng H, Ma L, Bandaranayaka N, Qin Z, Mann G, Kyeremeh K, Yu Y, Shepherd T, Naismith JH, O'Hagan D (2014) Identification of fluorinases from Streptomyces sp MA37, Norcardia brasiliensis, and Actinoplanes sp N902-109 by genome mining. ChemBioChem 15(3):364-368. https://doi.org/10.1002/cbic.201300732

Deng H, O'Hagan D, Schaffrath C (2004) Fluorometabolite biosynthesis and the fluorinase from Streptomyces cattleya. Nat Prod Rep 21(6):773-784. https://doi.org/10.1039/b415087m
Dennig A, Busto E, Kroutil W, Faber K (2015) Biocatalytic one-pot synthesis of L-tyrosine derivatives from monosubstituted benzenes, pyruvate, and ammonia. ACS Catal 5(12):7503-7506. https://doi.org/10.1021/acscatal.5b02129

Dezvarei S, Onoda H, Shoji O, Watanabe Y, Bell SG (2018) Efficient hydroxylation of cycloalkanes by co-addition of decoy molecules to variants of the cytochrome P450 CYP102A1. J Inorg Biochem 183:137-145. https://doi.org/10.1016/j.jinor gbio.2018.03.001

Dias MV, Huang F, Chirgadze DY, Tosin M, Spiteller D, Dry EF, Leadlay PF, Spencer JB, Blundell TL (2010) Structural basis for the activity and substrate specificity of fluoroacetyl-CoA thioesterase FlK. J Biol Chem 285(29):22495-22504. https://doi.org/10.1074/ jbc.M110.107177

Dietlein F, Kobe C, Hohberg M, Zlatopolskiy BD, Krapf P, Endepols H, Tager P, Hammes J, Heidenreich A, Persigehl T, Neumaier B, Drzezga A, Dietlein M (2020) Intraindividual comparison of ${ }^{18}$ F-PSMA-1007 with renally excreted PSMA ligands for PSMA PET imaging in patients with relapsed prostate cancer. J Nucl Med 61(5):729-734. https://doi.org/10.2967/jnumed.119.234898

Dong C, Deng H, Dorward M, Schaffrath C, O'Hagan D, Naismith JH (2003) Crystallization and X-ray diffraction of 5'-fluoro-5'deoxyadenosine synthase, a fluorination enzyme fromStreptomyces cattleya. Acta Crystallogr, Sect d: Biol Crystallogr 59(12):2292-2293. https://doi.org/10.1107/s0907444903019826

Dong C, Huang F, Deng H, Schaffrath C, Spencer JB, O'Hagan D, Naismith JH (2004) Crystal structure and mechanism of a bacterial fluorinating enzyme. Nature 427(6974):561-565. https://doi. org/10.1038/nature02280

Dos Santos LM, Bernard FL, Polesso BB, Pinto IS, Frankenberg CC, Corvo MC, Almeida PL, Cabrita E, Einloft S (2020) Designing silica xerogels containing RTIL for $\mathrm{CO}_{2}$ capture and $\mathrm{CO}_{2} / \mathrm{CH}_{4}$ separation: Influence of ILs anion, cation and cation side alkyl chain length and ramification. J Environ Manage 268:110340. https://doi.org/10.1016/j.jenvman.2020.110340

Dziedzic P, Cisneros JA, Robertson MJ, Hare AA, Danford NE, Baxter RH, Jorgensen WL (2015) Design, synthesis, and protein crystallography of biaryltriazoles as potent tautomerase inhibitors of macrophage migration inhibitory factor. J Am Chem Soc 137(8):2996-3003. https://doi.org/10.1021/ja512112j

Fang J, Hait D, Head-Gordon M, Chang MCY (2019) Chemoenzymatic platform for synthesis of chiral organofluorines based on type II aldolases. Angew Chem Int Ed Engl 58(34):11841-11845. https://doi.org/10.1002/anie.201906805

Feng X, Bello D, Lowe PT, Clark J, O'Hagan D (2019) Two 3'-O-betaglucosylated nucleoside fluorometabolites related to nucleocidin in Streptomyces calvus. Chem Sci 10(41):9501-9505. https://doi. org/10.1039/c9sc03374b

Fraioli F, Shankar A, Hyare H, Ferrazzoli V, Militano V, Samandouras G, Mankad K, Solda F, Zaccagna F, Mehdi E, Lyasheva M, Bomanji J, Novruzov F (2020) The use of multiparametric 18F-fluoro-L-3,4-dihydroxy-phenylalanine PET/MRI in posttherapy assessment of patients with gliomas. Nucl Med Commun 41(6):517-525. https://doi.org/10.1097/MNM.0000000000 001184

Fraley AE, Sherman DH (2018) Halogenase engineering and its utility in medicinal chemistry. Bioorg Med Chem Lett 28(11):19921999. https://doi.org/10.1016/j.bmcl.2018.04.066

France SP, Howard RM, Steflik J, Weise NJ, Mangas-Sanchez J, Montgomery SL, Crook R, Kumar R, Turner NJ (2018) Identification of novel bacterial members of the imine reductase enzyme family that perform reductive amination. ChemCatChem 10(3):510 514. https://doi.org/10.1002/cctc.201701408

Frank DJ, Zhao Y, Wong SH, Basudhar D, De Voss JJ, Ortiz de Montellano PR (2016) Cholesterol analogs with degradation-resistant alkyl side chains are effective Mycobacterium tuberculosis 
growth inhibitors. J Biol Chem 291(14):7325-7333. https://doi. org/10.1074/jbc.M115.708172

Fried J, Sabo EF (1954) $9 \alpha$-Fluoro derivatives of cortisone and hydrocortisone. J Am Chem Soc 76(5):1455-1456. https://doi.org/10. 1021/ja01634a101

Fryszkowska A, Devine PN (2020) Biocatalysis in drug discovery and development. Curr Opin Chem Biol 55:151-160. https://doi.org/ 10.1016/j.cbpa.2020.01.012

Fuenfgeld B, Machler P, Fischer DR, Esposito G, Rushing EJ, Kaufmann PA, Stolzmann P, Huellner MW (2020) Reference values of physiological ${ }^{18}$ F-FET uptake: Implications for brain tumor discrimination. PLoS ONE 15(4):e0230618. https://doi.org/10. 1371/journal.pone.0230618

Fujino H, Nagatomo M, Paudel A, Panthee S, Hamamoto H, Sekimizu $\mathrm{K}$, Inoue M (2017) Unified total synthesis of polyoxins J, L, and fluorinated analogues on the basis of decarbonylative radical coupling reactions. Angew Chem Int Ed Engl 56(39):11865-11869. https://doi.org/10.1002/anie.201706671

Gambini L, Baggio C, Udompholkul P, Jossart J, Salem AF, Perry JJP, Pellecchia M (2019) Covalent inhibitors of protein-protein interactions targeting lysine, tyrosine, or histidine residues. J Med Chem 62(11):5616-5627. https://doi.org/10.1021/acs.jmedchem. $9 \mathrm{~b} 00561$

Geissner A, Baumann L, Morley TJ, Wong AKO, Sim L, Rich JR, So PPL, Dullaghan EM, Lessard E, Iqbal U, Moreno M, Wakarchuk WW, Withers SG (2021) 7-Fluorosialyl glycosides are hydrolysis resistant but readily assembled by sialyltransferases providing easy access to more metabolically stable glycoproteins. ACS Cent Sci 7(2):345-354. https://doi.org/10.1021/acscentsci. 0c01589

Giesel FL, Hadaschik B, Cardinale J, Radtke J, Vinsensia M, Lehnert W, Kesch C, Tolstov Y, Singer S, Grabe N, Duensing S, Schafer M, Neels OC, Mier W, Haberkorn U, Kopka K, Kratochwil C (2017) F-18 labelled PSMA-1007: biodistribution, radiation dosimetry and histopathological validation of tumor lesions in prostate cancer patients. Eur J Nucl Med Mol Imaging 44(4):678-688. https://doi.org/10.1007/s00259-016-3573-4

Gillis EP, Eastman KJ, Hill MD, Donnelly DJ, Meanwell NA (2015) Applications of fluorine in medicinal chemistry. J Med Chem 58(21):8315-8359. https://doi.org/10.1021/acs.jmedchem.5b002 58

González-Martínez D, Cuetos A, Sharma M, García-Ramos M, Lavandera I, Gotor-Fernández V, Grogan G (2020a) Asymmetric synthesis of primary and secondary $\beta$-fluoro-arylamines using reductive aminases from fungi. ChemCatChem 12(9):24212425. https://doi.org/10.1002/cctc.201901999

González-Martínez D, Gotor V, Gotor-Fernández V (2020b) Chemoand stereoselective synthesis of fluorinated amino alcohols through one-pot reactions using alcohol dehydrogenases and amine transaminases. Adv Synth Catal 362(23):5398-5410. https://doi.org/10.1002/adsc.202000798

Grobbelaar N, Marion Meyer JJ (1990) Fluoroacetate production by Dichapetalum cymosum. J Plant Physiol 135(5):550-553. https:// doi.org/10.1016/s0176-1617(11)80634-6

Hagar M, Ahmed HA, Aljohani G, Alhaddad OA (2020) Investigation of some antiviral N-heterocycles as COVID 19 drug: Molecular docking and DFT calculations. Int J Mol Sci 21(11). https://doi. org/10.3390/ijms21113922

Hanaoka H, Ohshima Y, Yamaguchi A, Suzuki H, Ishioka NS, Higuchi T, Arano Y, Tsushima Y (2019) Novel ${ }^{18}$ F-labeled alpha-methylphenylalanine derivative with high tumor accumulation and ideal pharmacokinetics for tumor-specific imaging. Mol Pharm 16(8):3609-3616. https://doi.org/10.1021/acs.molpharmaceut. $9 \mathrm{~b} 00446$

Harper DB, O'Hagan D (1994) The fluorinated natural products. Nat Prod Rep 11(2):123-133. https://doi.org/10.1039/np9941100123
Hauer B (2020) Embracing nature's catalysts: a viewpoint on the future of biocatalysis. ACS Catal 10(15):8418-8427. https:// doi.org/10.1021/acscatal.0c01708

Holanda RJ, Deves C, Moreira-Dill LS, Guimaraes CL, Marttinelli LKB, Fernandes CFC, Medeiros PSM, Pereira SS, Honda ER, Stabeli RG, Santos DS, Soares AM, Pereira da Silva LH (2020) Plasmodium falciparum purine nucleoside phosphorylase as a model in the search for new inhibitors by high throughput screening. Int J Biol Macromol 165(Part B):1832-1841. https://doi.org/10.1016/j.ijbiomac.2020.10.062

Hong H, Spiteller D, Spencer JB (2008) Incorporation of fluoroacetate into an aromatic polyketide and its influence on the mode of cyclization. Angew Chem Int Ed Engl 47(32):6028-6032. https://doi.org/10.1002/anie.200801100

Honig M, Sondermann P, Turner NJ, Carreira EM (2017) Enantioselective chemo- and biocatalysis: Partners in retrosynthesis. Angew Chem Int Ed Engl 56(31):8942-8973. https://doi.org/ 10.1002/anie.201612462

Huang F, Haydock SF, Spiteller D, Mironenko T, Li TL, O'Hagan D, Leadlay PF, Spencer JB (2006) The gene cluster for fluorometabolite biosynthesis in Streptomyces cattleya: a thioesterase confers resistance to fluoroacetyl-coenzyme A. Chem Biol 13(5):475-484. https://doi.org/10.1016/j.chembiol.2006.02. 014

Huang S, Ma L, Tong MH, Yu Y, O’Hagan D, Deng H (2014) Fluoroacetate biosynthesis from the marine-derived bacterium Streptomyces xinghaiensis NRRL B-24674. Org Biomol Chem 12(27):4828-4831. https://doi.org/10.1039/c4ob00970c

Huang X, Garcia-Borras M, Miao K, Kan SBJ, Zutshi A, Houk KN, Arnold FH (2019) A biocatalytic platform for synthesis of chiral alpha-trifluoromethylated organoborons. ACS Cent Sci 5(2):270 276. https://doi.org/10.1021/acscentsci.8b00679

Huang Z, Guo Z, Xie D, Cao Z, Chen L, Wang H, Jiang L, Shen Q (2021) Rhizomucor miehei lipase-catalysed synthesis of cocoa butter equivalent from palm mid-fraction and stearic acid: Characteristics and feasibility as cocoa butter alternative. Food Chem 343:128407. https://doi.org/10.1016/j.foodchem.2020.128407

Iizaka Y, Sherman DH, Anzai Y (2021) An overview of the cytochrome P450 enzymes that catalyze the same-site multistep oxidation reactions in biotechnologically relevant selected actinomycete strains. Appl Microbiol Biotechnol 105(7):2647-2661. https:// doi.org/10.1007/s00253-021-11216-y

Izquierdo J, Jain AD, Abdulkadir SA, Schiltz GE (2019) Palladiumcatalyzed coupling reactions on functionalized 2-trifluoromethyl4-chromenone scaffolds. Synthesis of highly functionalized trifluoromethyl-heterocycles. Synthesis (Stuttg) 51(6):1342-1352. https://doi.org/10.1055/s-0037-1610669

Jansen BHE, Yaqub M, Voortman J, Cysouw MCF, Windhorst AD, Schuit RC, Kramer GM, van den Eertwegh AJM, Schwarte LA, Hendrikse NH, Vis AN, van Moorselaar RJA, Hoekstra OS, Boellaard R, Oprea-Lager DE (2019) Simplified methods for quantification of ${ }^{18} \mathrm{~F}$-DCFPyL uptake in patients with prostate cancer. J Nucl Med 60(12):1730-1735. https://doi.org/10.2967/ jnumed.119.227520

Ji D, Xiao C, Chen K, Zhou F, Gao Y, Zhang T, Ling H (2021) Solvent-free green fabrication of PVDF hollow fiber MF membranes with controlled pore structure via melt-spinning and stretching. J Membr Sci 621:118953. https://doi.org/10.1016/j.memsci.2020. 118953

Jiang G, Zhang Y, Powell MM, Zhang P, Zuo R, Zhang Y, Kallifidas D, Tieu AM, Luesch H, Loria R, Ding Y (2018) High-yield production of herbicidal thaxtomins and thaxtomin analogs in a nonpathogenic Streptomyces strain. Appl Environ Microbiol 84(11). https://doi.org/10.1128/AEM.00164-18

Kang D, Shao H, Chen G, Dong X, Qin S (2021) Fabrication of highly permeable PVDF loose nanofiltration composite membranes 
for the effective separation of dye/salt mixtures. J Membr Sci 621:118951. https://doi.org/10.1016/j.memsci.2020.118951

Kayushin AL, Tokunova JA, Fateev IV, Arnautova AO, Berzina MY, Paramonov AS, Lutonina OI, Dorofeeva EV, Antonov KV, Esipov RS, Mikhailopulo IA, Miroshnikov AI, Konstantinova ID (2021) Radical dehalogenation and purine nucleoside phosphorylase E. coli: How does an admixture of 2',3'-anhydroinosine hinder 2-fluoro-cordycepin synthesis. Biomolecules 11(4). https://doi.org/10.3390/biom11040539

Kharitonova M, Antonov K, Fateev I, Berzina M, Kaushin A, Paramonov A, Kotovskaya S, Andronova V, Konstantinova I, Galegov G, Charushin V, Miroshnikov A (2016) Chemoenzymatic synthesis of modified 2'-deoxy-2'-fluoro- $\beta$-D-arabinofuranosyl benzimidazoles and evaluation of their activity against herpes simplex virus type 1. Synthesis 49(05):1043-1052. https://doi. org/10.1055/s-0036-1588625

Khosravan A, Marani S, Sadeghi Googheri MS (2017) The effects of fluorine substitution on the chemical properties and inhibitory capacity of donepezil anti-Alzheimer drug; density functional theory and molecular docking calculations. J Mol Graph Model 71:124-134. https://doi.org/10.1016/j.jmgm.2016.11.013

Kim TH, Mehrabi P, Ren Z, Sljoka A, Ing C, Bezginov A, Ye L, Pomes R, Prosser RS, Pai EF (2017) The role of dimer asymmetry and protomer dynamics in enzyme catalysis. Science 355(6322). https://doi.org/10.1126/science.aag2355

Klopries S, Koopmans KR, Sanchez-Garcia E, Schulz F (2014) Biosynthesis with fluorine. ChemBioChem 15(4):495-497. https:// doi.org/10.1002/cbic.201300750

Koh E, Lee YT (2021) Preparation of an omniphobic nanofiber membrane by the self-assembly of hydrophobic nanoparticles for membrane distillation. Sep Purif Technol 259:118134. https:// doi.org/10.1016/j.seppur.2020.118134

Kojima K, Nakajima T, Taga N, Miyauchi A, Kato M, Matsumoto A, Ikeda T, Nakamura K, Kubota T, Mizukami H, Ono S, Onuki Y, Sato T, Osaka H, Muramatsu SI, Yamagata T (2019) Gene therapy improves motor and mental function of aromatic L-amino acid decarboxylase deficiency. Brain 142(2):322-333. https://doi. org/10.1093/brain/awy331

Langen KJ, Galldiks N, Hattingen E, Shah NJ (2017) Advances in neuro-oncology imaging. Nat Rev Neurol 13(5):279-289. https:// doi.org/10.1038/nrneurol.2017.44

Latham J, Brandenburger E, Shepherd SA, Menon BRK, Micklefield J (2018) Development of halogenase enzymes for use in synthesis. Chem Rev 118(1):232-269. https://doi.org/10.1021/acs.chemr ev.7b00032

Le Y, Gan Y, Fu Y, Liu J, Li W, Zou X, Zhou Z, Wang Z, Ouyang G, Yan L (2020) Design, synthesis and in vitro biological evaluation of quinazolinone derivatives as EGFR inhibitors for antitumor treatment. J Enzyme Inhib Med Chem 35(1):555-564. https:// doi.org/10.1080/14756366.2020.1715389

Lee JW, Oliveira MT, Jang HB, Lee S, Chi DY, Kim DW, Song CE (2016) Hydrogen-bond promoted nucleophilic fluorination: concept, mechanism and applications in positron emission tomography. Chem Soc Rev 45(17):4638-4650. https://doi.org/10.1039/ c6cs00286b

Lee ST, Cook D, Pfister JA, Allen JG, Colegate SM, Riet-Correa F, Taylor CM (2014) Monofluoroacetate-containing plants that are potentially toxic to livestock. J Agric Food Chem 62(30):73457354. https://doi.org/10.1021/jf500563h

Lena Sezici Y, Yetkiner E, Aykut Yetkiner A, Eden E, Attin R (2021) Comparative evaluation of fluoride varnishes, self-assembling peptide-based remineralization agent, and enamel matrix protein derivative on artificial enamel remineralization in vitro. Prog Orthod 22(1):4. https://doi.org/10.1186/s40510-020-00345-1

Leong LEX, Khan S, Davis CK, Denman SE, McSweeney CS (2017) Fluoroacetate in plants-a review of its distribution, toxicity to livestock and microbial detoxification. J Anim Sci Biotechnol 8:55. https://doi.org/10.1186/s40104-017-0180-6

Li B, Yun Y, Wang M, Li C, Yang W, Li J, Liu G (2021) Superhydrophobic polymer membrane coated by mineralized $\beta-\mathrm{FeOOH}$ nanorods for direct contact membrane distillation. Desalination 500:114889. https://doi.org/10.1016/j.desal.2020.114889

Li G, Lian J, Xue H, Jiang Y, Ju S, Wu M, Lin J (2020a) Yang L (2020a) Biocascade synthesis of L-tyrosine derivatives by coupling a thermophilic tyrosine phenol-lyase and L-lactate oxidase. Eur J Org Chem 8:1050-1054. https://doi.org/10. 1002/ejoc.202000061

Li N, Hu B, Wang A, Li H, Yin Y, Mao T, Xie T (2020b) Facile bioinspired preparation of fluorinase@ fluoridated hydroxyapatite nanoflowers for the biosynthesis of 5'-fluorodeoxy adenosine. Sustainability 12(1):431. https://doi.org/10.3390/su120 10431

Li WN, Fan DD (2020) Biocatalytic strategies for the production of ginsenosides using glycosidase: current state and perspectives. Appl Microbiol Biotechnol 104(9):3807-3823. https://doi.org/ 10.1007/s00253-020-10455-9

Li Y, Yue Y, Zhang H, Yang Z, Wang H, Tian S, Wang JB, Zhang Q, Wang W (2019) Harnessing fluoroacetate dehalogenase for defluorination of fluorocarboxylic acids: in silico and in vitro approach. Environ Int 131:104999. https://doi.org/10.1016/j. envint.2019.104999

Liang $\mathrm{H}, \mathrm{Hu} \mathrm{Z}$, Zhao Z, Chen D, Zhang H, Wang H, Wang X, Li Q, Guo X, Li H (2021) Dendrite-structured $\mathrm{FeF}_{2}$ consisting of closely linked nanoparticles as cathode for high-performance lithium-ion capacitors. J Energy Chem 55:517-523. https://doi. org/10.1016/j.jechem.2020.07.031

Liang S, Hammond GB, Xu B (2017) Hydrogen bonding: Regulator for nucleophilic fluorination. Chemistry 23(71):17850-17861. https://doi.org/10.1002/chem.201702664

Liu J, Li S, Aslam NA, Zheng F, Yang B, Cheng R, Wang N, Rozovsky S, Wang PG, Wang Q, Wang L (2019) Genetically encoding photocaged quinone methide to multitarget protein residues covalently in vivo. J Am Chem Soc 141(24):9458-9462. https:// doi.org/10.1021/jacs.9b01738

Liu L, Zhu Y, Chen Y, Chen H, Fan C, Mo Q, Yuan J (2020) One-pot cascade biotransformation for efficient synthesis of benzyl alcohol and its analogs. Chem Asian J 15(7):1018-1021. https://doi. org/10.1002/asia.201901680

Liu T, Yan N, Zhao H, Wang Z-X, Hu X-G (2018) Synthesis and antibacterial activity of 6(R)- and 6(S)-fluoropenibruguieramine As: Fluorine as a probe for testing the powerfulness of memory of chirality (MOC). J Fluorine Chem 207:18-23. https://doi.org/10. 1016/j.jfluchem.2018.01.002

Lizarme-Salas Y, Ariawan AD, Ratnayake R, Luesch H, Finch A, Hunter L (2020) Vicinal difluorination as a $\mathrm{C}=\mathrm{C}$ surrogate: an analog of piperine with enhanced solubility, photostability, and acetylcholinesterase inhibitory activity. Beilstein J Org Chem 16:2663-2670. https://doi.org/10.3762/bjoc.16.216

Lohmann P, Werner JM, Shah NJ, Fink GR, Langen KJ, Galldiks N (2019) Combined amino acid positron emission tomography and advanced aagnetic resonance imaging in glioma patients. Cancers (Basel) 11(2). https://doi.org/10.3390/cancers11020153

López-Iglesias M, González-Martínez D, Rodríguez-Mata M, Gotor V, Busto E, Kroutil W, Gotor-Fernández V (2017) Asymmetric biocatalytic synthesis of fluorinated pyridines through transesterification or transamination: Computational insights into the reactivity of transaminases. Adv Synth Catal 359(2):279-291. https://doi.org/10.1002/adsc.201600835

Lowe PT, Cobb SL, O'Hagan D (2019a) An enzymatic Finkelstein reaction: fluorinase catalyses direct halogen exchange. Org Biomol Chem 17(32):7493-7496. https://doi.org/10.1039/c9ob0 $1625 b$ 
Lowe PT, Dall'Angelo S, Devine A, Zanda M, O’Hagan D (2018) Enzymatic fluorination of biotin and tetrazine conjugates for pretargeting approaches to positron emission tomography imaging. ChemBioChem 19(18):1969-1978. https://doi.org/10.1002/ cbic. 201800234

Lowe PT, Dall'Angelo S, Fleming IN, Piras M, Zanda M, O'Hagan D (2019b) Enzymatic radiosynthesis of a ${ }^{18} \mathrm{~F}$-Glu-Ureido-Lys ligand for the prostate-specific membrane antigen (PSMA). Org Biomol Chem 17(6):1480-1486. https://doi.org/10.1039/c8ob0 3150 a

Lowe PT, Dall'Angelo S, Mulder-Krieger T, AP IJ, Zanda M, O'Hagan $\mathrm{D}$, (2017) A new class of fluorinated $\mathrm{A}_{2 \mathrm{~A}}$ adenosine receptor agonist with application to last-step enzymatic $\left[{ }^{18} \mathrm{~F}\right]$ fluorination for PET imaging. ChemBioChem 18(21):2156-2164. https://doi. org/10.1002/cbic.201700382

Lu X, Skomski D, Thompson KC, McNevin MJ, Xu W, Su Y (2019) Three-dimensional NMR spectroscopy of fluorinated pharmaceutical solids under ultrafast magic angle spinning. Anal Chem 91(9):6217-6224. https://doi.org/10.1021/acs.analchem.9b00884

Ma L, Bartholome A, Tong MH, Qin Z, Yu Y, Shepherd T, Kyeremeh K, Deng H, O'Hagan D (2015) Identification of a fluorometabolite from Streptomyces sp. MA37: (2R3S4S)-5-fluoro-2,3,4-trihydroxypentanoic acid. Chem Sci 6(2):1414-1419. https://doi. org/10.1039/c4sc03540b

Ma L, Li Y, Meng L, Deng H, Li Y, Zhang Q, Diao A (2016) Biological fluorination from the sea: discovery of a SAM-dependent nucleophilic fluorinating enzyme from the marine-derived bacterium Streptomyces xinghaiensis NRRL B24674. RSC Adv 6(32):27047-27051. https://doi.org/10.1039/c6ra00100a

Maglangit F, Fang Q, Leman V, Soldatou S, Ebel R, Kyeremeh K, Deng H (2019) Accramycin A, a new aromatic polyketide, from the soil bacterium, Streptomyces sp. MA37. Molecules 24(18). https://doi.org/10.3390/molecules24183384

Mahendra I, Hanaoka H, Yamaguchi A, Amartuvshin T, Tsushima Y (2020) Diagnosis of bladder cancer using ${ }^{18}$ F-labeled alphamethyl-phenylalanine tracers in a mouse model. Ann Nucl Med 34(5):329-336. https://doi.org/10.1007/s12149-020-01452-z

Makki MST, Abdel-Rahman RM, Alshammari NAH (2019) Synthesis of novel fluorine compounds substituted-4-thiazolidinones derived from rhodanine drug as highly bioactive probes. Curr Org Synth 16(3):413-422. https://doi.org/10.2174/1570179416 666190312150046

Maltais R, Ngueta Djiemeny A, Roy J, Barbeau X, Lambert JP, Poirier D (2020) Design and synthesis of dansyl-labeled inhibitors of steroid sulfatase for optical imaging. Bioorg Med Chem 28(7):115368. https://doi.org/10.1016/j.bmc.2020.115368

Mao Z, Liu L, Zhang Y, Yuan J (2020) Efficient synthesis of phenylacetate and 2-phenylethanol by modular cascade biocatalysis. ChemBioChem. https://doi.org/10.1002/cbic.202000182

Markakis K, Lowe PT, Davison-Gates L, O’Hagan D, Rosser SJ, Elfick A (2020) An engineered E. coli strain for direct in vivo fluorination. Chembiochem 21(13):1856-1860. https://doi.org/10.1002/ cbic. 202000051

Marner L, Nysom K, Sehested A, Borgwardt L, Mathiasen R, Henriksen OM, Lundemann M, Munck Af Rosenschold P, Thomsen C, Bogeskov L, Skjoth-Rasmussen J, Juhler M, Kruse A, Broholm H, Scheie D, Lauritsen T, Forman JL, Wehner PS, Hojgaard L, Law I (2019) Early postoperative ${ }^{18}$ F-FET PET/MRI for pediatric brain and spinal cord tumors. J Nucl Med 60(8):1053-1058. https://doi.org/10.2967/jnumed.118.220293

Marquez-Rodriguez AS, Guimaraes M, Mateus N, de Freitas V, Ballinas-Casarrubias ML, Fuentes-Montero ME, Salas E, Cruz L (2021) Disaccharide anthocyanin delphinidin 3-O-sambubioside from Hibiscus sabdariffa L.: Candida antarctica lipase B-catalyzed fatty acid acylation and study of its color properties. Food
Chem 344:128603. https://doi.org/10.1016/j.foodchem.2020. 128603

McAtee RC, Beatty JW, McAtee CC, Stephenson CRJ (2018) Radical chlorodifluoromethylation: Providing a motif for (Hetero)arene diversification. Org Lett 20(12):3491-3495. https://doi.org/10. 1021/acs.orglett.8b01249

Meanwell M, Silverman SM, Lehmann J, Adluri B, Wang Y, Cohen R, Campeau LC, Britton R (2020) A short de novo synthesis of nucleoside analogs. Science 369(6504):725-730. https://doi.org/ 10.1126/science.abb3231

Meanwell NA (2018) Fluorine and fluorinated motifs in the design and application of bioisosteres for drug design. J Med Chem 61(14):5822-5880. https://doi.org/10.1021/acs.jmedchem.7b017 88

Mei H, Han J, Fustero S, Medio-Simon M, Sedgwick DM, Santi C, Ruzziconi R, Soloshonok VA (2019) Fluorine-containing drugs approved by the FDA in 2018. Chemistry 25(51):11797-11819. https://doi.org/10.1002/chem.201901840

Mei H, Han J, Klika KD, Izawa K, Sato T, Meanwell NA, Soloshonok VA (2020a) Applications of fluorine-containing amino acids for drug design. Eur J Med Chem 186:111826. https://doi.org/10. 1016/j.ejmech.2019.111826

Mei H, Remete AM, Zou Y, Moriwaki H, Fustero S, Kiss L, Soloshonok VA, Han J (2020b) Fluorine-containing drugs approved by the FDA in 2019. Chin Chem Lett 31(9):2401-2413. https://doi. org/10.1016/j.cclet.2020.03.050

Mennie KM, Banik SM, Reichert EC, Jacobsen EN (2018) Catalytic diastereo- and enantioselective fluoroamination of alkenes. J Am Chem Soc 140(14):4797-4802. https://doi.org/10.1021/ jacs. 8 b02143

Menon BRK, Richmond D, Menon N (2020) Halogenases for biosynthetic pathway engineering: Toward new routes to naturals and non-naturals. Catalysis Reviews:1-59. https://doi.org/10.1080/ 01614940.2020 .1823788

Minges H, Sewald N (2020) Recent advances in synthetic application and engineering of halogenases. ChemCatChem 12(18):44504470. https://doi.org/10.1002/cctc.202000531

Miranda-Rojas S, Fernández I, Kästner J, Toro-Labbé A, Mendizábal F (2018) Unraveling the nature of the catalytic power of fluoroacetate dehalogenase. ChemCatChem 10(5):1052-1063. https:// doi.org/10.1002/cctc. 201701517

Miyamoto M, Miyamoto T, Saitou J, Sato T (2020) Longitudinal study of striatal aromatic L-amino acid decarboxylase activity in patients with idiopathic rapid eye movement sleep behavior disorder. Sleep Med 68:50-56. https://doi.org/10.1016/j.sleep. 2019.09.013

Molinaro C, Phillips EM, Xiang B, Milczek E, Shevlin M, Balsells J, Ceglia S, Chen J, Chen L, Chen Q, Fei Z, Hoerrner S, Qi J, de Lera RM, Tan L, Wan B, Yin J (2019) Synthesis of a CGRP receptor antagonist via an asymmetric synthesis of 3-fluoro4-aminopiperidine. J Org Chem 84(12):8006-8018. https://doi. org/10.1021/acs.joc.9b00569

Moschner J, Stulberg V, Fernandes R, Huhmann S, Leppkes J, Koksch B (2019) Approaches to obtaining fluorinated alpha-amino acids. Chem Rev 119(18):10718-10801. https://doi.org/10.1021/acs. chemrev.9b00024

Mossine AV, Tanzey SS, Brooks AF, Makaravage KJ, Ichiishi N, Miller JM, Henderson BD, Erhard T, Bruetting C, Skaddan MB, Sanford MS, Scott PJH (2020) Synthesis of high-molar-activity $\left[{ }^{18} \mathrm{~F}\right] 6$-fluoro-L-DOPA suitable for human use via $\mathrm{Cu}$-mediated fluorination of a BPin precursor. Nat Protoc 15(5):1742-1759. https://doi.org/10.1038/s41596-020-0305-9

Muller K, Faeh C, Diederich F (2007) Fluorine in pharmaceuticals: looking beyond intuition. Science 317(5846):1881-1886. https:// doi.org/10.1126/science.1131943 
Munck Af Rosenschold M, Johannesson P, Nikitidis A, Tyrchan C, Chang HF, Ronn R, Chapman D, Ullah V, Nikitidis G, Glader P, Kack H, Bonn B, Wagberg F, Bjorkstrand E, Andersson U, Swedin L, Rohman M, Andreasson T, Bergstrom EL, Jiang F, Zhou XH, Lundqvist AJ, Malmberg A, Ek M, Gordon E, Pettersen A, Ripa L, Davis AM (2019) Discovery of the oral leukotriene $\mathrm{C} 4$ synthase inhibitor $(1 \mathrm{~S}, 2 \mathrm{~S})-2-(\{5-[(5-$ Chloro-2,4-difluorophenyl)(2-fluoro-2-methylpropyl)amino]3-methoxypyrazin-2-yl \} carbonyl)cyclopropanecarboxylic acid (AZD9898) as a new treatment for asthma. J Med Chem 62(17):7769-7787. https://doi.org/10.1021/acs.jmedchem.9b005 55

Nakashima M, Suzuki N, Shiraishi E, Iwashita H (2019) TAK-915, a phosphodiesterase $2 \mathrm{~A}$ inhibitor, ameliorates the cognitive impairment associated with aging in rodent models. Behav Brain Res 376:112192. https://doi.org/10.1016/j.bbr.2019.112192

Nashiru O, Zechel DL, Stoll D, Mohammadzadeh T, Warren RAJ, Withers SG (2001) $\beta$-Mannosynthase: Synthesis of $\beta$-mannosides with a mutant $\beta$-mannosidase. Angew Chem Int Ed 113(2):431434. https://doi.org/10.1002/1521-3757(20010119)113:2\% 3c431::AID-ANGE431\%3e3.0.CO;2-Z

Nayak K, Tripathi BP (2021) Molecularly grafted PVDF membranes with in-air superamphiphilicity and underwater superoleophobicity for oil/water separation. Sep Purif Technol 259:118068. https://doi.org/10.1016/j.seppur.2020.118068

Ni C, Hu J (2016) The unique fluorine effects in organic reactions: recent facts and insights into fluoroalkylations. Chem Soc Rev 45(20):5441-5454. https://doi.org/10.1039/c6cs00351f

O'Hagan D, Deng H (2015) Enzymatic fluorination and biotechnological developments of the fluorinase. Chem Rev 115(2):634-649. https://doi.org/10.1021/cr500209t

O'Hagan D, Schaffrath C, Cobb SL, Hamilton JT, Murphy CD (2002) Biochemistry: biosynthesis of an organofluorine molecule. Nature 416(6878):279. https://doi.org/10.1038/416279a

O'Hagan D, Harper BD (1999) Fluorine-containing natural products. J. Fluorine Chem 100(1-2):127-133. https://doi.org/10.1016/ s0022-1139(99)00201-8

Obach RS, Walker GS, Brodney MA (2016) Biosynthesis of fluorinated analogs of drugs using human cytochrome P450 enzymes followed by deoxyfluorination and quantitative nuclear magnetic resonance spectroscopy to improve metabolic stability. Drug Metab Dispos 44(5):634-646. https://doi.org/10.1124/dmd.116. 069310

Odar C, Winkler M, Wiltschi B (2015) Fluoro amino acids: A rarity in nature, yet a prospect for protein engineering. Biotechnol $\mathbf{J}$ 10(3):427-446. https://doi.org/10.1002/biot.201400587

Olgun A (2019) Selective targeting of signet ring cell adenocarcinomas. Med Hypotheses 133:109380. https://doi.org/10.1016/j. mehy.2019.109380

Paguigan ND, Al-Huniti MH, Raja HA, Czarnecki A, Burdette JE, Gonzalez-Medina M, Medina-Franco JL, Polyak SJ, Pearce CJ, Croatt MP, Oberlies NH (2017) Chemoselective fluorination and chemoinformatic analysis of griseofulvin: Natural vs fluorinated fungal metabolites. Bioorg Med Chem 25(20):5238-5246. https://doi.org/10.1016/j.bmc.2017.07.041

Palmer-Brown W, Dunne B, Ortin Y, Fox MA, Sandford G, Murphy CD (2017) Biotransformation of fluorophenyl pyridine carboxylic acids by the model fungus Cunninghamella elegans. Xenobiotica 47(9):763-770. https://doi.org/10.1080/00498254.2016. 1227109

Pant P, Pathak A, Jayaram B (2021) Symmetric nucleosides as potent purine nucleoside phosphorylase inhibitors. J Phys Chem B 125(11):2856-2862. https://doi.org/10.1021/acs.jpcb.0c10553

Parker WB, Allan PW, Waud WR, Hong J, Gilbert-Ross M, Achyut BR, Joshi D, Behbahani T, Rab R, Ealick SE, Sorscher EJ (2020) The use of Trichomonas vaginalis purine nucleoside phosphorylase to activate fludarabine in the treatment of solid tumors. Cancer Chemother Pharmacol 85(3):573-583. https:// doi.org/10.1007/s00280-019-04018-7

Patil MD, Grogan G, Bommarius A, Yun H (2018) Oxidoreductasecatalyzed synthesis of chiral amines. ACS Catal 8(12):1098511015. https://doi.org/10.1021/acscatal.8b02924

Phillips RS, Craig S, Kovalevsky A, Gerlits O, Weiss K, Iorgu AI, Heyes DJ, Hay S (2019) Pressure and temperature effects on the formation of aminoacrylate intermediates of tyrosine phenol-lyase demonstrate reaction dynamics. ACS Catal 10(3):1692-1703. https://doi.org/10.1021/acscatal.9b03967

Pinson A, Yarbrough AL, Bush JM, Cabanlong CV, Shoeib A, Jackson BK, Fukuda S, Gogoi J, Fantegrossi WE, McCain K, Prather PL, Fujiwara R, Radominska-Pandya A (2020) Metabolism, CB1 cannabinoid receptor binding and in vivo activity of synthetic cannabinoid 5F-AKB48: Implications for toxicity. Pharmacol Biochem Behav 195:172949. https://doi. org/10.1016/j.pbb.2020.172949

Pomeisl K, Krecmerova M, Pohl R, Snoeck R, Andrei G (2019) Synthesis of fluorinated acyclic nucleoside phosphonates with 5-azacytosine base moiety. Tetrahedron 75(39):130529. https:// doi.org/10.1016/j.tet.2019.130529

Preshlock S, Tredwell M, Gouverneur V (2016) ${ }^{18}$ F-labeling of arenes and heteroarenes for applications in positron emission tomography. Chem Rev 116(2):719-766. https://doi.org/10. 1021/acs.chemrev.5b00493

Pupo G, Ibba F, Ascough DMH, Vicini AC, Ricci P, Christensen KE, Pfeifer L, Morphy JR, Brown JM, Paton RS, Gouverneur V (2018) Asymmetric nucleophilic fluorination under hydrogen bonding phase-transfer catalysis. Science 360(6389):638-642. https://doi.org/10.1126/science.aar7941

Pupo G, Vicini AC, Ascough DMH, Ibba F, Christensen KE, Thompson AL, Brown JM, Paton RS, Gouverneur V (2019) Hydrogen bonding phase-transfer catalysis with potassium fluoride: Enantioselective synthesis of beta-fluoroamines. J Am Chem Soc 141(7):2878-2883. https://doi.org/10.1021/jacs.8b12568

Quintard A, Sperandio C, Rodriguez J (2018) Modular enantioselective synthesis of an advanced pentahydroxy intermediate of antimalarial bastimolide A and of fluorinated and chlorinated analogues. Org Lett 20(17):5274-5277. https://doi.org/10. 1021/acs.orglett.8b02213

Raskin SE, Tranby EP, Ludwig S, Okunev I, Frantsve-Hawley J, Boynes S (2021) Survival of silver diamine fluoride among patients treated in community dental clinics: a naturalistic study. BMC Oral Health 21(1):35. https://doi.org/10.1186/ s12903-020-01379-x

Reichel M, Karaghiosoff K (2020) Reagents for selective fluoromethylation: A challenge in organofluorine chemistry. Angew Chem Int Ed Engl 59(30):12268-12281. https://doi.org/10.1002/anie. 201913175

Remete AM, Nonn M, Fustero S, Fülöp F, Kiss L (2018) Synthesis of fluorinated amino acid derivatives through late-stage deoxyfluorinations. Tetrahedron 74(44):6367-6418. https://doi.org/ 10.1016/j.tet.2018.09.021

Ren S, Cheng X, Zhang Y, Zhuang J, Ma L (2020) Advances in biosynthesis of fluorinated products. Acta Microbiol Sin 61(3):524-538. https://doi.org/10.13343/j.cnki.wsxb.20200284

Rentmeister A, Arnold FH, Fasan R (2009) Chemo-enzymatic fluorination of unactivated organic compounds. Nat Chem Biol 5(1):26-28. https://doi.org/10.1038/nchembio.128

Rivera-Chavez J, Raja HA, Graf TN, Burdette JE, Pearce CJ, Oberlies NH (2017) Biosynthesis of fluorinated peptaibols using a site-directed building block incorporation approach. J Nat Prod 80(6):1883-1892. https://doi.org/10.1021/acs.jnatprod. $7 \mathrm{~b} 00189$ 
Robbins T, Liu YC, Cane DE, Khosla C (2016) Structure and mechanism of assembly line polyketide synthases. Curr Opin Struct Biol 41:10-18. https://doi.org/10.1016/j.sbi.2016.05.009

Rocha JF, Pina AF, Sousa SF, Cerqueira NMFSA (2019) PLPdependent enzymes as important biocatalysts for the pharmaceutical, chemical and food industries: a structural and mechanistic perspective. Catal Sci Technol 9(18):4864-4876. https:// doi.org/10.1039/c9cy01210a

Romanov V, Isohashi K, Alobthani G, Beshr R, Horitsugi G, Kanai Y, Naka S, Watabe T, Shimosegawa E, Hatazawa J (2020) Evaluation of the total distribution volume of ${ }^{18} \mathrm{~F}$-FBPA in normal tissues of healthy volunteers by non-compartmental kinetic modeling. Ann Nucl Med 34(3):155-162. https://doi. org/10.1007/s12149-019-01427-9

Rousseau E, Wilson D, Lacroix-Poisson F, Krauze A, Chi K, Gleave M, McKenzie M, Tyldesley S, Goldenberg SL, Benard F (2019) A prospective study on ${ }^{18} \mathrm{~F}$-DCFPyL PSMA PET/CT imaging in biochemical recurrence of prostate cancer. J Nucl Med 60(11):1587-1593. https://doi.org/10.2967/jnumed.119. 226381

Rowe SP, Campbell SP, Mana-Ay M, Szabo Z, Allaf ME, Pienta KJ, Pomper MG, Ross AE, Gorin MA (2020a) Prospective evaluation of PSMA-targeted ${ }^{18} \mathrm{~F}$-DCFPyL PET/CT in men with biochemical failure after radical prostatectomy for prostate cancer. J Nucl Med 61(1):58-61. https://doi.org/10.2967/jnumed.119. 226514

Rowe SP, Li X, Trock BJ, Werner RA, Frey S, DiGianvittorio M, Bleiler JK, Reyes DK, Abdallah R, Pienta KJ, Gorin MA, Pomper MG (2020b) Prospective comparison of PET imaging with PSMA-targeted ${ }^{18} \mathrm{~F}$-DCFPyL versus $\mathrm{Na}^{18} \mathrm{~F}$ for bone lesion detection in patients with metastatic prostate cancer. J Nucl Med 61(2):183-188. https://doi.org/10.2967/jnumed.119.227793

Saadi J, Wennemers H (2016) Enantioselective aldol reactions with masked fluoroacetates. Nat Chem 8(3):276-280. https://doi.org/ $10.1038 /$ nchem. 2437

Sadurni A (2018) Gilmour R (2018) Stereocontrolled synthesis of 2-fluorinated $C$-glycosides. European J Org Chem 27-28:36843687. https://doi.org/10.1002/ejoc.201800618

Sanada M, Miyano T, Iwadare S, Williamson JM, Arison BH, Smith JL, Douglas AW, Liesch JM, Inamine E (1986) Biosynthesis of fluorothreonine and fluoroacetic acid by the thienamycin producer Streptomyces Cattleya. J Antibiot (tokyo) 39(2):259-265. https://doi.org/10.7164/antibiotics.39.259

Sandoval BA, Hyster TK (2020) Emerging strategies for expanding the toolbox of enzymes in biocatalysis. Curr Opin Chem Biol 55:45-51. https://doi.org/10.1016/j.cbpa.2019.12.006

Scheidt F, Schafer M, Sarie JC, Daniliuc CG, Molloy JJ, Gilmour R (2018) Enantioselective, catalytic vicinal difluorination of alkenes. Angew Chem, Int Ed 57(50):16431-16435. https://doi.org/ 10.1002/anie.201810328

Schmitt S, Delamare J, Tirel O, Fillesoye F, Dhilly M, Perrio C (2017) $\mathrm{N}-\left[{ }^{18} \mathrm{~F}\right]$-FluoropropylJDTic for kappa-opioid receptor PET imaging: Radiosynthesis, pre-clinical evaluation, and metabolic investigation in comparison with parent JDTic. Nucl Med Biol 44:50-61. https://doi.org/10.1016/j.nucmedbio.2016.09.005

Scott TA, Heine D, Qin Z, Wilkinson B (2017) An L-threonine transaldolase is required for L-threo-beta-hydroxy-alpha-amino acid assembly during obafluorin biosynthesis. Nat Commun 8:15935. https://doi.org/10.1038/ncomms 15935

Senn HM, O'Hagan D, Thiel W (2005) Insight into enzymatic C-F bond formation from QM and QM/MM calculations. J Am Chem Soc 127(39):13643-13655. https://doi.org/10.1021/ja053875s

Sester A, Stuer-Patowsky K, Hiller W, Kloss F, Lutz S, Nett M (2020) Biosynthetic plasticity enables production of fluorinated aurachins. ChemBioChem 21(16):2268-2273. https://doi.org/10. 1002/cbic. 202000166
Shah M, Paramshivam G, Mehta A, Singh S, Chugh A, Prashar A, Chugh VK (2018) Comparative assessment of conventional and light-curable fluoride varnish in the prevention of enamel demineralization during fixed appliance therapy: a split-mouth randomized controlled trial. Eur J Orthod 40(2):132-139. https:// doi.org/10.1093/ejo/cjx037

Shahmohammadi S, Fulop F, Forro E (2020) Efficient synthesis of new fluorinated beta-amino acid enantiomers through lipasecatalyzed hydrolysis. Molecules 25(24). https://doi.org/10.3390/ molecules 25245990

Shao CL, Linington RG, Balunas MJ, Centeno A, Boudreau P, Zhang C, Engene N, Spadafora C, Mutka TS, Kyle DE, Gerwick L, Wang CY, Gerwick WH (2015) Bastimolide A, a potent antimalarial polyhydroxy macrolide from the marine cyanobacterium Okeania hirsuta. J Org Chem 80(16):7849-7855. https://doi.org/ 10.1021/acs.joc.5b01264

Shimizu K, Kaira K, Higuchi T, Hisada T, Yokobori T, Oyama T, Asao T, Tsushima Y, Shirabe K (2019) Relationship between tumor immune markers and fluorine-18-alpha-methyltyrosine $\left(\left[{ }^{18} \mathrm{~F}\right]\right.$ FAMT) uptake in patients with lung cancer. Mol Imaging Biol. https://doi.org/10.1007/s11307-019-01456-w

Sisila V, Puhazhselvan P, Aarthy M, Sakkeeshyaa G, Saravanan P, Kamini NR, Ayyadurai N (2021) Esterification of polymeric carbohydrate through congener cutinase-like biocatalyst. Appl Biochem Biotechnol 193(1):19-32. https://doi.org/10.1007/ s12010-020-03415-6

Snoch W, Stępień K, Prajsnar J, Staroń J, Szaleniec M, Guzik M (2019) Influence of chemical modifications of polyhydroxyalkanoatederived fatty acids on their antimicrobial properties. Catalysts 9(6):510. https://doi.org/10.3390/catal9060510

Sooklal SA, De Koning C, Brady D, Rumbold K (2020) Identification and characterisation of a fluorinase from Actinopolyspora mzabensis. Protein Expr Purif 166:105508. https://doi.org/10. 1016/j.pep.2019.105508

Stachelska-Wierzchowska A, Wierzchowski J (2020) Non-typical nucleoside analogs as fluorescent and fluorogenic indicators of purine-nucleoside phosphorylase activity in biological samples. Anal Chim Acta 1139:119-128. https://doi.org/10.1016/j.aca. 2020.09.018

Stadlbauer S, Steinborn C, Klemd A, Hattori F, Ohmori K, Suzuki K, Huber R, Wolf P, Grundemann C (2018) Impact of green tea catechin ECG and its synthesized fluorinated analogue on prostate cancer cells and stimulated immunocompetent cells. Planta Med 84(11):813-819. https://doi.org/10.1055/s-0044-102099

Sudileti M, Nagaripati S, Gundluru M, Chintha V, Aita S, Wudayagiri R, Chamarthi N, Cirandur SR (2019) rGO-SO3H catalysed green synthesis of fluoro-substituted aminomethylene bisphosphonates and their anticancer, molecular docking studies. ChemistrySelect 4(44):13006-13011. https://doi.org/10.1002/slct.201903191

Sun H, Yeo WL, Lim YH, Chew X, Smith DJ, Xue B, Chan KP, Robinson RC, Robins EG, Zhao H, Ang EL (2016) Directed evolution of a fluorinase for improved fluorination efficiency with a non-native substrate. Angew Chem, Int Ed 55(46):14277-14280. https://doi.org/10.1002/anie.201606722

Sun H, Zhao H, Ang EL (2018) A coupled chlorinase-fluorinase system with a high efficiency of trans-halogenation and a shared substrate tolerance. Chem Commun (camb) 54(68):9458-9461. https://doi.org/10.1039/c8cc04436h

Swallow S (2015) Fluorine in medicinal chemistry. Prog Med Chem 54:65-133. https://doi.org/10.1016/bs.pmch.2014.11.001

Tang ML, Zhou L, Chang J, Hu ZH, Qin Y, Sun X (2016) Differential metabolism of 3FDT and docetaxel in RLMs, rats, and HLMs. Eur J Med Chem 113:81-91. https://doi.org/10.1016/j.ejmech. 2016.02.007

Tao H, Mori T, Wei X, Matsuda Y, Abe I (2021) One polyketide synthase, two distinct products: Trans-acting enzyme-controlled 
product divergence in calbistrin biosynthesis. Angew Chem Int Ed 60(16):8851-8858. https://doi.org/10.1002/anie.202016525

Tao L, Li Y, Guo X, Dong L, Liu L, Wang Q, Yu X, Song C, Chang J (2020) Synthesis and anti-CVB3 activity of 4-amino acid derivative substituted pyrimidine nucleoside analogues. Bioorg Med Chem Lett 30(1):126770. https://doi.org/10.1016/j.bmcl. 2019.126770

Thompson S, Fleming IN, O'Hagan D (2016a) Enzymatic transhalogenation of dendritic RGD peptide constructs with the fluorinase. Org Biomol Chem 14(11):3120-3129. https://doi.org/10. 1039/c6ob00239k

Thompson S, McMahon SA, Naismith JH, O'Hagan D (2016b) Exploration of a potential difluoromethyl-nucleoside substrate with the fluorinase enzyme. Bioorg Chem 64:37-41. https:// doi.org/10.1016/j.bioorg.2015.11.003

Thompson S, Onega M, Ashworth S, Fleming IN, Passchier J, O'Hagan D (2015) A two-step fluorinase enzyme mediated ${ }^{18} \mathrm{~F}$ labelling of an RGD peptide for positron emission tomography. Chem Commun (camb) 51(70):13542-13545. https://doi.org/ $10.1039 / \mathrm{c} 5 \mathrm{cc} 05013 \mathrm{~h}$

Thomsen M, Vogensen SB, Buchardt J, Burkart MD, Clausen RP (2013) Chemoenzymatic synthesis and in situ application of S-adenosyl-L-methionine analogs. Org Biomol Chem 11(43):7606-7610. https://doi.org/10.1039/c3ob41702f

Thuronyi BW, Chang MC (2015) Synthetic biology approaches to fluorinated polyketides. Acc Chem Res 48(3):584-592. https:// doi.org/10.1021/ar500415c

Thuronyi BW, Privalsky TM, Chang MCY (2017) Engineered fluorine metabolism and fluoropolymer production in living cells. Angew Chem Int Ed 56(44):13637-13640. https://doi.org/10. 1002/anie.201706696

Timofeev VI, Fateev IV, Kostromina MA, Abramchik YA, Konstantinova ID, Volkov VV, Lykoshin DD, Mikheeva OO, Muravieva TI, Esipov RS, Kuranova IP (2020) The comparative analysis of the properties and structures of purine nucleoside phosphorylases from thermophilic bacterium Thermus thermophilus HB27. J Biomol Struct Dyn:1-16. https://doi.org/10.1080/ 07391102.2020 .1848628

Toit JMP (1943) The isolation of the toxic principle "potassium cymonate" from "Gifblaar" Dichapetalum cymosum (Hook) Engl. 1943. Onderstepoort J Vet Sci Anim Ind 18:203-206

Tong W, Huang Q, Li M, Wang J-b (2019) Enzyme-catalyzed C-F bond formation and cleavage. Bioresour Bioprocess 6(1):46. https://doi.org/10.1186/s40643-019-0280-6

Troelsen NS, Shanina E, Gonzalez-Romero D, Dankova D, Jensen ISA, Sniady KJ, Nami F, Zhang H, Rademacher C, Cuenda A, Gotfredsen CH, Clausen MH (2020) The 3F library: Fluorinated $\mathrm{Fsp}^{3}$-rich fragments for expeditious ${ }^{19} \mathrm{~F}$-NMR based screening. Angew Chem, Int Ed 59(6):2204-2210. https://doi. org/10.1002/anie.201913125

Tu C, Zhou J, Peng L, Man S, Ma L (2020) Self-assembled nanoaggregates of fluorinases demonstrate enhanced enzymatic activity, thermostability and reusability. Biomater Sci 8(2):648-656. https://doi.org/10.1039/c9bm00402e

Vaughan MD, Su Z, Daub E, Honek JF (2016) Intriguing cellular processing of a fluorinated amino acid during protein biosynthesis in Escherichia coli. Org Biomol Chem 14(38):89428946. https://doi.org/10.1039/c6ob01690a

Walker MC, Thuronyi BW, Charkoudian LK, Lowry B, Khosla C, Chang MC (2013) Expanding the fluorine chemistry of living systems using engineered polyketide synthase pathways. Science 341(6150):1089-1094. https://doi.org/10.1126/scien ce. 1242345

Wang H, Liang J, Yue Q, Li L, Shi Y, Chen G, Li YZ, Bian X, Zhang Y, Zhao G, Ding X (2021) Engineering the acyltransferase domain of epothilone polyketide synthase to alter the substrate specificity. Microb Cell Fact 20(1):86. https://doi.org/10.1186/ s12934-021-01578-3

Wang JB, Ilie A, Yuan S, Reetz MT (2017) Investigating substrate scope and enantioselectivity of a defluorinase by a stereochemical probe. J Am Chem Soc 139(32):11241-11247. https://doi. org/10.1021/jacs.7b06019

Wang Z, Matthews H (2020) Translational incorporation of modified phenylalanines and tyrosines during cell-free protein synthesis. RSC Adv 10(19):11013-11023. https://doi.org/10.1039/d0ra0 $0655 \mathrm{f}$

Weeks AM, Chang MC (2012) Catalytic control of enzymatic fluorine specificity. Proc Natl Acad Sci U S A 109(48):19667-19672. https://doi.org/10.1073/pnas.1212591109

Weeks AM, Keddie NS, Wadoux RD, O'Hagan D, Chang MC (2014) Molecular recognition of fluorine impacts substrate selectivity in the fluoroacetyl-CoA thioesterase FlK. Biochemistry 53(12):2053-2063. https://doi.org/10.1021/bi4015049

Weeks AM, Wang N, Pelton JG, Chang MCY (2018) Entropy drives selective fluorine recognition in the fluoroacetyl-CoA thioesterase from Streptomyces cattleya. Proc Natl Acad Sci U S A 115(10):E2193-E2201. https://doi.org/10.1073/pnas.17170 77115

Weissman KJ (2016) Genetic engineering of modular PKSs: from combinatorial biosynthesis to synthetic biology. Nat Prod Rep 33(2):203-230. https://doi.org/10.1039/c5np00109a

Won Y, Jeon H, Pagar AD, Patil MD, Nadarajan SP, Flood DT, Dawson PE, Yun H (2019) In vivo biosynthesis of tyrosine analogs and their concurrent incorporation into a residue-specific manner for enzyme engineering. Chem Commun (camb) 55(100):1513315136. https://doi.org/10.1039/c9cc08503c

Wu L, Maglangit F, Deng H (2020a) Fluorine biocatalysis. Curr Opin Chem Biol 55:119-126. https://doi.org/10.1016/j.cbpa.2020.01. 004

Wu L, Tong MH, Kyeremeh K, Deng H (2020b) Identification of 5-fluoro-5-deoxy-ribulose as a shunt fluorometabolite in Streptomyces sp. MA37. Biomolecules 10(7). https://doi.org/10.3390/ biom 10071023

Wu L, Tong MH, Raab A, Fang Q, Wang S, Kyeremeh K, Yu Y, Deng $\mathrm{H}$ (2020) An unusual metal-bound 4-fluorothreonine transaldolase from Streptomyces sp. MA37 catalyses promiscuous transaldol reactions. Appl Microbiol Biotechnol 104(9):38853896. https://doi.org/10.1007/s00253-020-10497-Z

Wu Q, Cai J, Zhao F, Zhou Z, Yang D, Qin Z (2020d) Synthesis and insecticidal activity of the fluorinated galegine analogues. Nat Prod Res:1-5. https://doi.org/10.1080/14786419.2020.1836631

Xiao Y, Wang Y, Zhu W, Yao J, Sun C, Militky J, Venkataraman M, Zhu G (2021) Development of tree-like nanofibrous air filter with durable antibacterial property. Sep Purif Technol 259:118135. https://doi.org/10.1016/j.seppur.2020.118135

Xie J, Hase WL (2016) Organic chemistry. Rethinking the $S_{N} 2$ reaction. Science 352(6281):32-33. https://doi.org/10.1126/science. aaf5172

Yamaguchi A, Hanaoka H, Higuchi T, Tsushima Y (2020) Selective synthesis of L-2- $\left[{ }^{18} \mathrm{~F}\right]$ fluoro-alpha-methylphenylalanine via copper-mediated ${ }^{18} \mathrm{~F}$-fluorination of (mesityl)(aryl)iodonium salt. J Labelled Comp Radiopharm 63(8):368-375. https://doi.org/10. $1002 /$ jlcr. 3840

Yamamoto T, Umegawa Y, Yamagami M, Suzuki T, Tsuchikawa H, Hanashima S, Matsumori N, Murata M (2019) The perpendicular orientation of amphotericin B methyl ester in hydrated lipid bilayers supports the barrel-stave model. Biochemistry 58(17):2282-2291. https://doi.org/10.1021/acs.biochem.9b00180

Yang X, Wu T, Phipps RJ, Toste FD (2015) Advances in catalytic enantioselective fluorination, mono-, di-, and trifluoromethylation, and trifluoromethylthiolation reactions. Chem Rev 115(2):826870. https://doi.org/10.1021/cr500277b 
Yang ZY, Hao YC, Hu SQ, Zong MH, Chen Q, Li N (2021) Direct reductive amination of biobased furans to $\mathrm{N}$-substituted furfurylamines by engineered reductive aminase. Adv Synth Catal 363(4):1033-1037. https://doi.org/10.1002/adsc.202001495

Yeo WL, Chew X, Smith DJ, Chan KP, Sun H, Zhao H, Lim YH, Ang EL (2017) Probing the molecular determinants of fluorinase specificity. Chem Commun (camb) 53(17):2559-2562. https:// doi.org/10.1039/c6cc09213f

Yimmut K, Homchoo K, Hinchiranan N (2018) Poly(butyl acrylate-cofluorinated acrylate)-graft-natural rubber: Synthesis and application as compatibilizer for natural rubber/poly(butyl acrylate-cofluorinated acrylate) films. Colloids Surf A 540:11-22. https:// doi.org/10.1016/j.colsurfa.2017.12.062

Youn J-W, Albermann C, Sprenger GA (2020) In vivo cascade catalysis of aromatic amino acids to the respective mandelic acids using recombinant E. coli cells expressing hydroxymandelate synthase (HMS) from Amycolatopsis mediterranei. Mol Catal 483:110713. https://doi.org/10.1016/j.mcat.2019.110713

Yue Y, Chen J, Bao L, Wang J, Li Y, Zhang Q (2020) Fluoroacetate dehalogenase catalyzed dehalogenation of halogenated carboxylic acids: A QM/MM approach. Chemosphere 254:126803. https://doi.org/10.1016/j.chemosphere.2020.126803

Zechel DL, Reid SP, Nashiru O, Mayer C, Stoll D, Jakeman DL, Warren RA, Withers SG (2001) Enzymatic synthesis of carbon-fluorine bonds. J Am Chem Soc 123(18):4350-4351. https://doi. org/10.1021/ja005855q

Zhang B, Liu J, Gao D, Yu X, Wang J, Lei X (2019a) A fluorine scan on the $\mathrm{Zn}^{2+}$-binding thiolate side chain of HDAC inhibitor largazole: Synthesis, biological evaluation, and molecular modeling. Eur J Med Chem 182:111672. https://doi.org/10.1016/j.ejmech. 2019.111672

Zhang H, Tian S, Yue Y, Li M, Tong W, Xu G, Chen B, Ma M, Li Y, Wang J-b (2020a) Semirational design of fluoroacetate dehalogenase RPA 1163 for kinetic resolution of $\alpha$-fluorocarboxylic acids on a gram scale. ACS Catal 10(5):3143-3151. https://doi.org/10. 1021/acscatal.9b04804

Zhang J, Huang X, Zhang RK, Arnold FH (2019b) Enantiodivergent alpha-amino C-H fluoroalkylation catalyzed by engineered cytochrome P450s. J Am Chem Soc 141(25):9798-9802. https:// doi.org/10.1021/jacs.9b04344

Zhang Q, Dall'Angelo S, Fleming IN, Schweiger LF, Zanda M, O'Hagan D (2016) Last-step enzymatic $\left[{ }^{18} \mathrm{~F}\right]$-fluorination of cysteine-tethered RGD peptides using modified barbas linkers. Chemistry 22(31):10998-11004. https://doi.org/10.1002/chem. 201601361

Zhang S, Klementz D, Zhu J, Makitrynskyy R, Ola Pasternak AR, Gunther S, Zechel DL, Bechthold A (2019c) Genome mining reveals the origin of a bald phenotype and a cryptic nucleocidin gene cluster in Streptomyces asterosporus DSM 41452. J Biotechnol 292:23-31. https://doi.org/10.1016/j.jbiotec.2018.12.016

Zhang XX, Gao Y, Hu XS, Ji CB, Liu YL, Yu JS (2020b) Recent advances in catalytic enantioselective synthesis of fluorinated $\alpha$ and $\beta$-amino acids. Adv Synth Catal 362(22):4763-4793. https:// doi.org/10.1002/adsc.202000966

Zhao S, Liang T, Zhu L, Yang L, Liu T, Fu J, Wang B, Zhan J, Liu L (2019) Fate of 6:2 fluorotelomer sulfonic acid in pumpkin (Cucurbita maxima L.) based on hydroponic culture: Uptake, translocation and biotransformation. Environ Pollut 252(Pt A):804-812. https://doi.org/10.1016/j.envpol.2019.06.020

Zhao S, Liu T, Zhu L, Yang L, Zong Y, Zhao H, Hu L, Zhan J (2021) Formation of perfluorocarboxylic acids (PFCAs) during the exposure of earthworms to 6:2 fluorotelomer sulfonic acid (6:2 FTSA). Sci Total Environ 760:143356. https://doi.org/10.1016/j. scitotenv.2020.143356
Zhao X, Noro J, Fu J, Silva C, Cavaco-Paulo A (2019b) Strategies for the synthesis of fluorinated polyesters. RSC Adv 9(4):1799_ 1806. https://doi.org/10.1039/c8ra10341k

Zhdankin VV, Luzzio FA, Monsen PJ (2017) Selective fluorination of natural products. Arkivoc 2017(1):117-147. https://doi.org/10. 24820/ark.5550190.p009.917

Zheng W, Chen K, Wang Z, Cheng X, Xu G, Yang L, Wu J (2020) Construction of a highly diastereoselective aldol reaction system with L-threonine aldolase by computer-assisted rational molecular modification and medium engineering. Org Lett 22(15):57635767. https://doi.org/10.1021/acs.orglett.0c01792

Zheng W, Yu H, Fang S, Chen K, Wang Z, Cheng X, Xu G, Yang L, Wu J (2021) Directed evolution of L-threonine aldolase for the diastereoselective synthesis of $\beta$-hydroxy- $\alpha$-amino acids. ACS Catal 11(6):3198-3205. https://doi.org/10.1021/acscatal.0c04949

Zhong J, Li W, Qian J, Fu C, Chu H, Xu J, Ran X, Nie W (2021) Modulation of the interfacial architecture enhancing the efficiency and energy density of ferroelectric nanocomposites via the irradiation method. J Colloid Interface Sci 586:30-38. https://doi.org/10. 1016/j.jcis.2020.10.066

Zhou Y, Wang J, Gu Z, Wang S, Zhu W, Acena JL, Soloshonok VA, Izawa K, Liu H (2016) Next generation of fluorine-containing pharmaceuticals, compounds currently in phase II-III clinical trials of major pharmaceutical companies: New structural trends and therapeutic areas. Chem Rev 116(2):422-518. https://doi. org/10.1021/acs.chemrev.5b00392

Zhu HQ, Tang XL, Zheng RC, Zheng YG (2020a) Purification and biochemical characterization of a tyrosine phenol-lyase from Morganella morganii. Appl Biochem Biotechnol. https://doi. org/10.1007/s12010-020-03301-1

Zhu W, Doubleday PF, Catlin DS, Weerawarna PM, Butrin A, Shen S, Wawrzak Z, Kelleher NL, Liu D, Silverman RB (2020b) A remarkable difference that one fluorine atom confers on the mechanisms of inactivation of human ornithine aminotransferase by two cyclohexene analogues of gamma-aminobutyric acid. J Am Chem Soc 142(10):4892-4903. https://doi.org/10.1021/jacs. 0c00193

Zhu X, Robinson DA, McEwan AR, O'Hagan D, Naismith JH (2007) Mechanism of enzymatic fluorination in Streptomyces cattleya. J Am Chem Soc 129(47):14597-14604. https://doi.org/10.1021/ ja0731569

Zhu Y, Wang J, Mou P, Yan Y, Chen M, Tang Y (2021) Genome mining of cryptic tetronate natural products from a PKS-NRPS encoding gene cluster in Trichoderma harzianum $\mathrm{t}-22$. Org Biomol Chem 19(9):1985-1990. https://doi.org/10.1039/d0ob02545c

Zou L, Ruan Y, Jiang W, Yan N, Liu DY, Yu CY, Hu XG (2019) Switchable regioselectivity in the opening of aziridine by fluoride: DFT calculation and synthesis of fluorinated piperidines. ChemistrySelect 4(43):12683-12688. https://doi.org/10.1002/ slct.201903403

Zuo R, Zhang Y, Huguet-Tapia JC, Mehta M, Dedic E, Bruner SD, Loria R, Ding Y (2016) An artificial self-sufficient cytochrome P450 directly nitrates fluorinated tryptophan analogs with a different regio-selectivity. Biotechnol J 11(5):624-632. https://doi. org/10.1002/biot.201500416

Publisher's note Springer Nature remains neutral with regard to jurisdictional claims in published maps and institutional affiliations. 